\title{
Justification of Crew Function and Function Capability for Long Duration Deep Space Habitation
}

\author{
Robert L. Howard, Jr. ${ }^{1}$ \\ NASA Johnson Space Center, Houston, Texas, 77058
}

\begin{abstract}
There are currently no established standards or guidelines that define the functions to be present in habitats for use beyond Low Earth Orbit (LEO), or for the capabilities of those functions. There is limited human experience with long duration space habitation, none of which is beyond LEO. There is significantly less experience with even short duration human habitation beyond LEO. Studies since the Apollo program that have proposed long duration habitats have applied inconsistent functionality, yet these functions have substantial implications for spacecraft mass and volume. There are also numerous aspects of human space flight beyond LEO that have implications for these functions. This paper develops a method for design teams to identify and justify the functions and capabilities to include in long duration habitats intended for use beyond LEO. Finally, human-in-the-loop testing methods are recommended for use in the early spacecraft design stages to ensure that the habitat will successfully provide the intended functions and capabilities.
\end{abstract}

$\begin{array}{lll} & & \\ A R E D & = & \text { Advanced Resistive Exercise Device } \\ B F S & = & \text { Backup Flight Software } \\ C E V I S & = & \text { Cycle Ergometer with Vibration Isolation System } \\ E C L S & = & \text { Environmental Control and Life Support } \\ E V A & = & \text { Extra-Vehicular Activity } \\ \text { GNC } & = & \text { Guidance Navigation and Control } \\ G P C & = & \text { General Purpose Computer } \\ H D U & = & \text { Habitat Demonstration Unit } \\ H E R A & = & \text { Human Exploration Research Analog } \\ H I T L & = & \text { Human-in-the-Loop Testing } \\ I S R U & = & \text { In-Situ Resource Utilization } \\ I S S & = & \text { International Space Station } \\ L E O & = & \text { Low Earth Orbit } \\ L E R & = & \text { Lunar Electric Rover } \\ M M S E V & = & \text { Multi-Mission Space Exploration Vehicle } \\ M P L M & = & \text { Multi-Purpose Logistics Module } \\ N E A & = & \text { Near Earth Asteroid } \\ O R U & = & \text { Orbital Replacement Unit } \\ P A S S & = & \text { Primary Avionics Software System } \\ R F I D & = & \text { Radio Frequency Identification } \\ R M & = & \text { Redundancy Management } \\ S M E & = & \text { Subject Matter Expert } \\ T 2 & = & \text { Treadmill 2 } \\ V R & = & \text { Virtual Reality } \\ & & \end{array}$

${ }^{1}$ AIAA Senior Member, Habitability Design Center Manager, Habitability and Human Factors Branch, 2101 NASA Parkway, Mail Code SF3

1

American Institute of Aeronautics and Astronautics 


$$
\begin{array}{lll}
W C S & = & \text { Waste Containment System } \\
W H C & = & \text { Waste and Hygiene Compartment }
\end{array}
$$

\section{Introduction}

NASA is leading the human spaceflight community to conduct long duration missions beyond Low Earth Orbit (LEO). While NASA has experienced short duration human spaceflight beyond LEO in the late 1960s and early 1970s, long duration flight beyond LEO imposes significant habitability impacts that were not addressed in the Apollo program. Agencies and companies around the world are grappling with the implications of the habitats necessary to sustain crews for these missions. One of the most common questions faced by human factors practitioners on these design teams is, "how large does the habitat have to be?" Crew size and mission duration are only part of the answer. The size of such a spacecraft is heavily driven by what crew functions are needed onboard the habitat. By definition, these habitats will have specific functionality. But what will that functionality be? Concepts that have been proposed around the world, from NASA Design Reference Missions, to those of various aerospace companies have varied widely in the functionality described in their habitats. As this is a new domain, there is no complete set of internationally recognized standards for engineers to draw upon to determine what crew functions must be present in a long duration habitat. This paper will propose a framework to develop rationale or justification for specific crew functions and functional capabilities for long duration deep space habitation.

\section{Historical Human Space Flight}

The only long duration spacecraft to have flown to date are Mir and the International Space Station, both of which are in LEO and neither of which have housed a crew for greater than 500 consecutive days. Further, at only about $12^{1 / 2}$ days, Apollo 17 sets the current duration record for human habitation beyond LEO.

Neither the two space stations, nor Apollo, constitute a sufficient experience base to merely use historical examples as the sole predictor of crew function and function capability. In the decades since Apollo, dozens of human exploration studies have proposed long duration habitats, but the allocation of functions within these concepts has not been identical. In fact, prior NASA studies, both mockup and paper studies, have applied inconsistent functionality to deep space habitats. For instance, the Habitat Demonstration Unit (HDU), created under the Constellation program to represent a lunar outpost and later modified to represent a Deep Space Habitat, co-located life science research with the medical workstation in its Deep Space Habitat asteroid mission configuration. Initially, the HDU also included a dedicated spacesuit maintenance workstation in the lunar version (in addition to a general maintenance workstation focused on the habitat) but dropped it in the Deep Space Habitat version. By comparison, the Vertical Habitat created under the Lunar Habitat Mockups Project, a concept study initiated in the early days of the NASA Constellation lunar program, separated life science from medical operations and included a suit maintenance workstation. Crew functions heavily affect overall spacecraft volume and configuration because each function occupies physical space in the spacecraft and depending on the capabilities of these functions, they may or may not be able to share volume with other crew functions.

For purposes of this paper, Crew Function refers to the habitat's accommodation of a general crew task, such as meal consumption or maintenance. Function Capability describes the level of performance of a particular function. For instance, one habitat might support the function of medical operations with a shoe box sized first aid kit, while another might support the same function of medical operations with a surgical table, advanced telemedicine cameras, large screen displays, surgical robots, and eight space shuttle mid deck lockers of medical instruments and supplies. The two habitats support the same function, but with very different capabilities.

\section{Implications of Human Space Flight Beyond LEO}

There are key implications of human space flight beyond LEO that must be considered to determine appropriate crew functions. Mission durations, transit and abort time, medical contingencies, maintenance contingencies, perishables accommodation, and multi-vehicle architectures all pose implications for crew functions.

Mission durations can be a result of both the mission objective and location of the destination. Orbital phasing in particular will limit duration options. In Cislunar space, the period of the destination orbit will require the spacecraft to remain at Cislunar space before beginning a transit burn to return to Earth. On the lunar surface, there are additional phasing considerations for an ascent vehicle to launch and rendezvous with a Cislunar or lunar orbiting Earth return vehicle. For interstellar missions such as to Near Earth Asteroids (NEAs) or Mars vicinity where the spacecraft has 
departed Earth's solar orbit, there is an orbital alignment period where the spacecraft must remain at its destination before it can depart to return to Earth. For missions within the Mars system such as Mars surface or where there is a crew departure from the orbit of the transfer vehicle, there is a phasing constraint where the crew must remain at destination before it can return to the transfer vehicle. These phasing-induced constraints require the crew to remain at their mission destination for cyclic intervals of time.

Even when the vehicle is able to return to Earth, transit time must be considered. In LEO, when the crew begins a nominal entry sequence they can be on the ground in less than an hour. If the crew is returning in a separate entry vehicle from the spacecraft used for the orbital day, there can be a period of a few hours to days before entry burn. However, destinations beyond LEO are significantly further away and crew time to return to Earth increases sharply. Transit time to/from Cislunar space is on the order of three to seven days, depending on propulsion system. Transit time varies considerably for NEAs depending on their orbital location. Potential destinations studied by NASA in the 2010-2014 timeframe include 100-200+ day transits. This approaches transit times to reach the Mars system, generally in the 6-8 month range. Additionally, depending on the orbital location of the Mars transit time, the transit time from Mars surface launch to transit habitat docking can range from one to five days.

The combination of mission duration and transit times generally define the time the crew is away from Earth. However, aborts will also have an impact. In the event of an in-flight emergency in LEO, the crew can abandon ISS and be on the ground in hours; less time if an arbitrary landing location is acceptable. It is approximately the same time as a nominal entry transit. However, once a spacecraft has begun a transit burn to depart LEO, an immediate abort is no longer necessarily possible. In Cislunar or lunar missions, the spacecraft may have to continue on to the lunar vicinity before it can begin a transit back to Earth. The same may be true for transits into interstellar space. This means the spacecraft may have to provide nominal habitation capability for an extended period of time after the emergency that triggered an abort. In worst cases, this duration may equal the original mission duration, effectively negating the traditional concept of a mission abort.

Beyond the impacts of duration, transit, and abort, which impact the time the crew is in space, other factors have strong impacts on the functions that must be present on the vehicle. Medical contingencies, while fortunately rare, also pose strong implications. Medical contingencies include the initial response, post-response recovery, and return to Earth. The medical capability must be able to provide a response in time to administer care before the patient's condition deteriorates. Additionally, if the crew member requires post-emergency treatment (e.g. broken limb), there must be adequate provision. Finally, Earth entry vehicles (e.g. Orion, Soyuz) and surface ascent vehicles (e.g. Mars Ascent Vehicle) are not designed with ambulance capability and thus certain medical conditions may preclude crew transfer to those vehicles, thereby requiring a period of recovery time before the crew can transition to such a spacecraft.

Just as the crew can experience unplanned contingencies, so can the spacecraft hardware. Maintenance contingencies also have a significant impact. Three basic maintenance philosophies have been used in LEO, but they do not fully extend to deep space. NASA spacecraft up through the shuttle program employed a philosophy of Redundancy Management (RM) to achieve a program requirement for "fail operational/fail-safe," meaning after one failure in a system, the shuttle could still continue its mission and after a second failure, the vehicle could still return to Earth safely [1]. The shuttle therefore carried redundant versions of subsystem components. For instance, it carried five General Purpose Computers (GPCs), running two different software architectures, the Primary Avionics Software System (PASS) and the Backup Flight Software (BFS). The shuttle launched with three GPCs running PASS software with another running BFS. In the event of a failure, another computer would take over and if enough computers failed the mission would be aborted and the crew would return to Earth early. Once the shuttle was back on the ground, ground personnel would perform any needed maintenance and repairs. This is not possible with the International Space Station, since it never returns to Earth. Instead, most components of the ISS are designed as Orbital Replaceable Units (ORUs), meaning they can be easily removed and replaced with a spare. The faulty unit can then be returned to Earth for servicing. New Earth-to-orbit capsules such as the Orion spacecraft, do have some redundancy, but there is a greater emphasis on Reliability, using components and systems with significantly reduced probability of failure.

For long mission durations beyond LEO, the probability of failure over time is so great that Reliability is not sufficient. The mass impact of carrying redundant systems or enough ORU spares to cover all potential failures is also prohibitive. This implies there must be a greater level of maintenance onboard the spacecraft, potentially rising to include some forms of what the Department of Defense classifies as Intermediate Level and Depot Level maintenance and repair. Intermediate Level includes, "limited repair of commodity-oriented assemblies and end items (e.g., electronic "black boxes" and mechanical components); job shop, bay, and production line operations for special requirements; repair of subassemblies such as circuit boards; software maintenance; and fabrication or manufacture 3

American Institute of Aeronautics and Astronautics 
of repair parts, assemblies, and components" and Depot Level includes, "major repair, overhaul, or complete rebuilding of weapon systems, end items, parts, assemblies, and subassemblies; manufacture of parts; technical assistance; and testing." [2] Accommodating this level of maintenance capability may have a profound impact on the entire spacecraft.

Spaceflight beyond LEO also has significant impact for perishables. Food shelf life is an obvious immediate concern, but food is not the only quantity with limited lifetime. Many medicines also have expiration dates. Some science payloads, particularly those involving live payloads or biological samples, can also be considered perishables. Even some maintenance and repair supplies have limited lifetimes. Maximizing the lifetimes of these perishable items may require special accommodation such as climate controlled environments or other environmental protection.

Many architectures for human missions beyond LEO involve multi-spacecraft vehicle configurations where the long duration habitat is joined by other - often short duration - spacecraft. A transit habitat may, in some architectures, travel to/from Mars alone, but it is joined at the Mars end of the transit by landers. At the Earth departure or Cislunar staging end, it is joined by logistics modules, Orion or other capsule spacecraft, and potentially the Deep Space Gateway or other staging platform. Similarly, a surface base involves pressurized rovers, landers, logistics modules, and potentially other pressurized surface elements in addition to the outpost itself. The long duration spacecraft effectively becomes a "mother ship" or "home base" in these architectures. This means that the long duration spacecraft is the one that provides resources that the other spacecraft cannot.

\section{Duty of the Mother Ship or Home Base}

In a deep space transit architecture, the transit habitat serves as the mother ship. In a planetary architecture, the outpost is the home base. In either case, it serves as the location for primary crew habitation - the crew lives there with the exception of relatively short periods in the other spacecraft. Thus, it must provide all life support and other subsystem functions. It is also the site for mission coordination and planning activities, as well as psychosocial support. While some stowage may or may not also be in an attached logistics module, the transit habitat or outpost will generally contain the most frequently accessed stowage and trash/waste. It must support both nominal and contingency operations for both the crew and itself, including potentially extensive medical and maintenance capabilities.

However, in a deep space architecture, neither a transit habitat nor an outpost is a solitary spacecraft unto itself. Both are visited by, and/or permanently attached to, other spacecraft. These other vehicles invariably rely on the "mother ship" or "home base" for support they cannot provide for themselves. For instance, the crew in a surface rover will have access to very limited medical and exercise capabilities and will experience some deconditioning during the time the crew is onboard. When they return to their home base, the surface outpost, they will use the habitat's greater exercise capability for rehabilitative purposes and will use the superior medical capability to address any medical issues that may have arisen during the rover excursion. They may also rely on the outpost's maintenance capabilities to service the rover. They may rely on the habitat's science capabilities to conduct in-situ research on a subset of samples collected by the rover (e.g. those in excess of the Earth return cargo capacity and thus not destined for return to Earth). Finally, they may rely on the habitat's stowage capabilities, including internal volume for stowage processing, to restock the rover in preparation for subsequent excursions. In microgravity, a docked logistics module will rely on the transit habitat for attitude control and potentially life support for its pressurized element. Even an Earth access spacecraft such as the Orion capsule may rely on the habitat for contingency servicing in the event of an inflight maintenance issue that creates safety risks for return to Earth. Depending on whether it is on the surface or in space, a lander vehicle may rely on either the microgravity or surface habitat for contingency maintenance and resupply/servicing.

\section{Crew Function and Capability Working Definitions}

Crew functions can be grouped into general categories of living functions and working functions. Living functions include private habitation, hygiene, waste collection, meal preparation, meal consumption, group socialization and recreation, exercise, and medical operations. Living functions can be defined as the functions that must occur as a consequence of the crew being alive, irrespective of the mission of the spacecraft. Working functions can be defined as those as that derive directly from the mission of the spacecraft. They include scientific research, robotics / teleoperations, EVA operations, spacecraft monitoring and commanding, mission planning, maintenance, and logistics operations.

In this paper, the purpose of each of the aforementioned functions will be described. Then, examples of each function will be described as implemented in current or historic spacecraft, or in spacecraft prototypes. A matrix will 
be introduced that can be used in design teams to document justifications for each crew function and its associated function capability, thus providing a more clear rationale for the inclusion or exclusion of various capabilities.

As previously mentioned, there are no internationally accepted standards here, so invariably different teams will select different crew functions and function capabilities, but this template will reduce the likelihood of errors of omission and will help to establish a conscious decision-making path.

\section{Function Capability Justification}

It is not unusual in human spaceflight for a capability to be introduced early in a spacecraft's design cycle only to have it immediately dismissed for mass, cost, or other reasons. Sometimes such a dismissal is later discovered to be an ill-informed error. Such errors can lead to cost increases, schedule delays, and risks to mission success or in worst cases crew survival. The temptation to dismiss (or even outright forget) a function or capability that is not readily justified (often by a non-expert) can be fraught with potential danger. Humans systems are especially vulnerable to this occurrence. They are far less deterministic than spacecraft structures or avionics, whose functional capabilities are relatively easy to quantify and justify. Propellant loading requirements, for instance, can be calculated deterministically and justified based on mission performance objectives. It is far more difficult to quantify exactly how much volume a crew member needs for sleeping, or how much video display surface area is needed for performing teleoperations, or how many microscopes must be onboard to enable mission science. Yet underestimation in these living and working functional domains can result in increased crew frustration, reduced mission performance, and potentially even play leading or contributing roles in triggering life or mission-threatening contingencies. (The collision of the Progress freighter with the Russian Mir space station was in part related to inadequate function capability of the TORU workstation used on the Mir to remotely fly the Progress [3]. Mir permanently lost one of its science modules and one crew quarters as a result of the collision. [4])

Having the right subject matter experts (SMEs) in the room is critical. It is, for instance, no more sufficient to have a single "scientist" to represent the domains of science than it is to have a single "engineer" in the room to represent all spacecraft subsystems.

This is illustrated most significantly by the Lunar Habitat Mockups Project. The project team provided early mockup concepts for a lunar outpost in the 2004-2005 timeframe. Its first study repurposed leftover hardware from a prior NASA project (Bioplex) and outfitted a horizontally oriented module as a lunar outpost. Astronaut Mario Runco is shown in Fig. 1 in the mockup's galley. However, the design team included no science representation and failed to include any science functionality in the design. This was not realized until the mockup was evaluated. A follow-on low fidelity mockup, a vertical configuration corrected this error but included only two work volumes, shown in Fig. 2 , one designated broadly for biological science and the other for physical science.

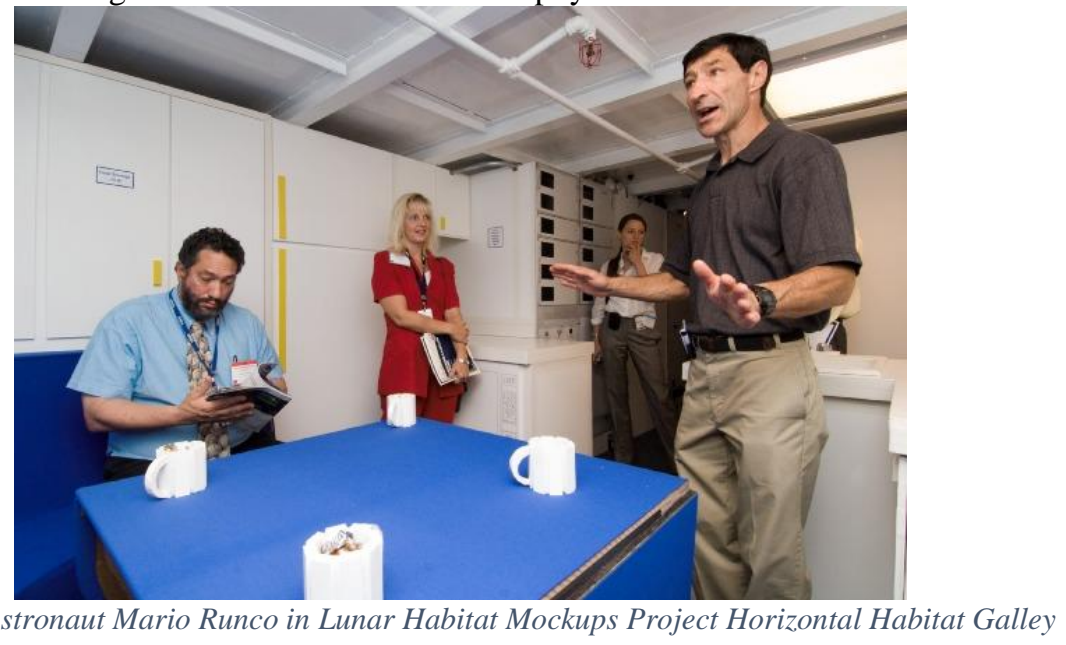




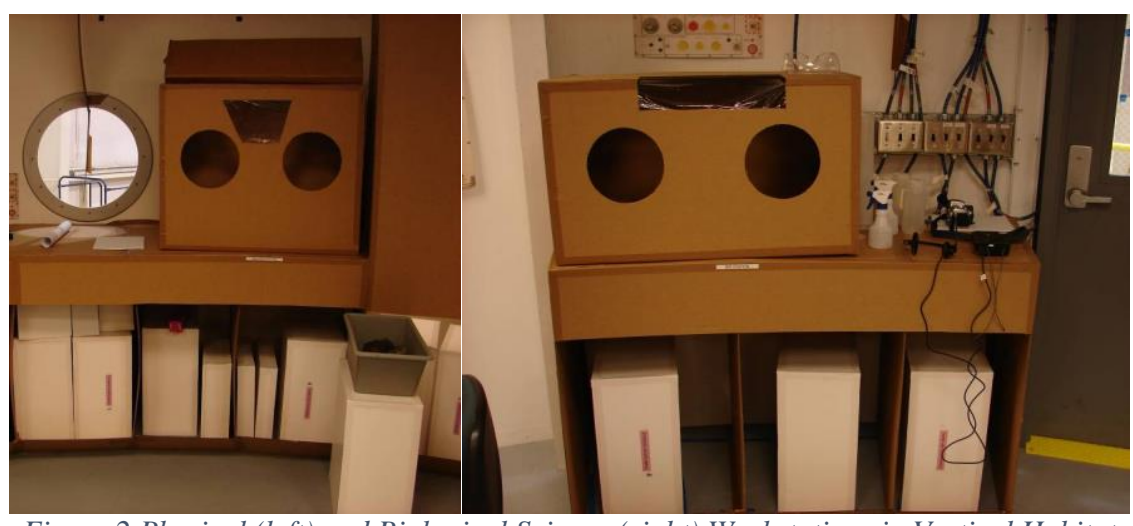

Figure 2 Physical (left) and Biological Science (right) Workstations in Vertical Habitat

This continued to be the level of functional definition provided for science throughout the Constellation program. One of the final outpost layouts developed prior to the cancellation of the Constellation program was the Lunar Surface Scenario 12.1 lunar outpost, shown in Fig. 3, which included a Geo Lab workstation and a Bio Lab workstation, with no provision for any other science capability, with the limited exceptions that some medical research could be accomplished in the medical workstation and with the crew exercise equipment, and that teleoperated science could be conducted from the cockpits of the Lunar Electric Rovers.

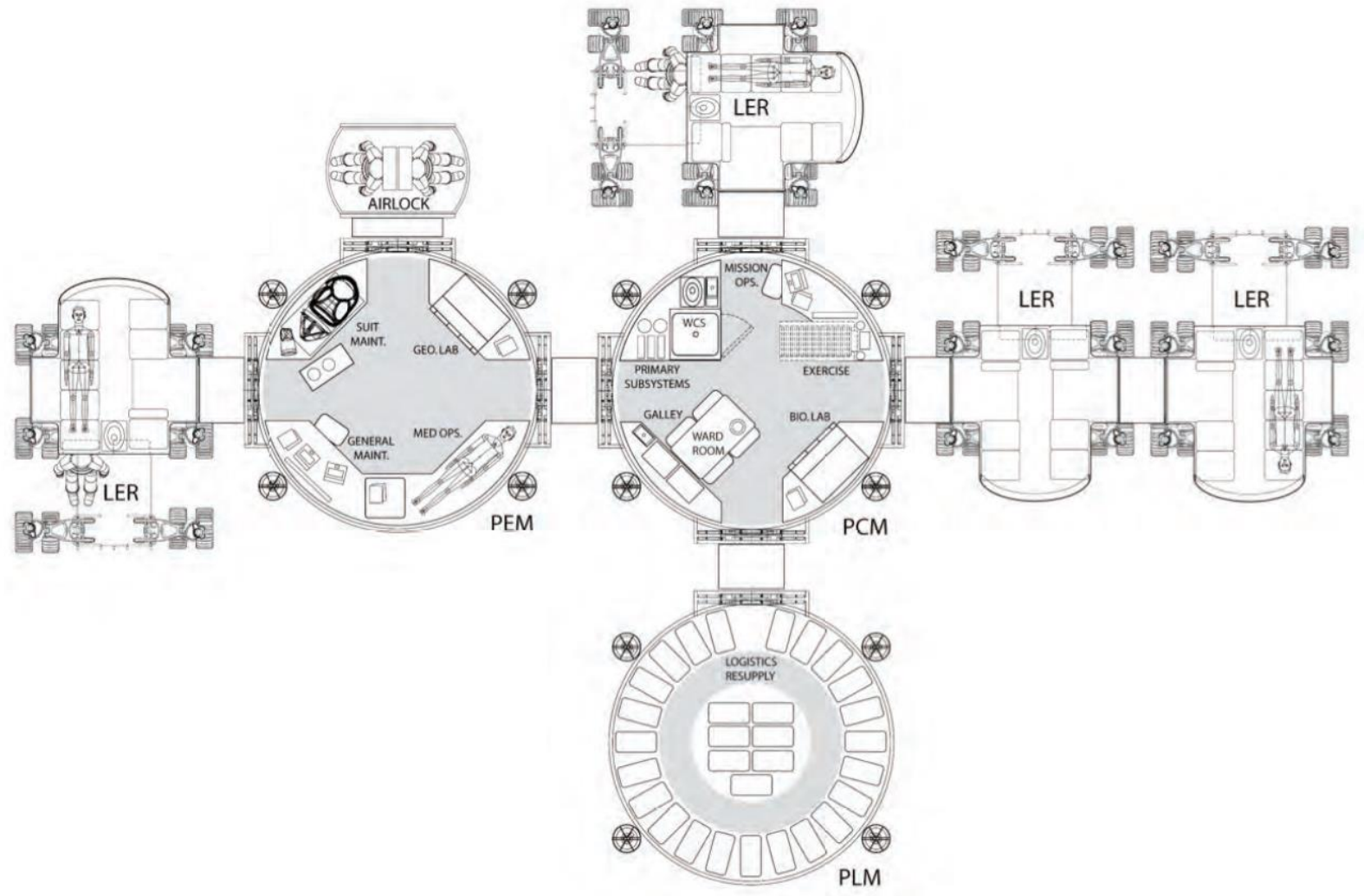

Figure 3 Scenario 12.1 Lunar Outpost

No volume had been allocated in the outpost for sciences such as chemistry, acoustics, cryogenics, combustion, fluid science, materials science, physics, and optics, despite the fact that such sciences carry active experiments today on ISS and the potential easily exists for the same sciences to have research interests on the Moon. Since advocates of those disciplines are not typically funded to participate in early habitat concept development, the need for their inclusion was not apparent to the design teams.

Spacecraft design teams can obtain more consistent, objective, and inclusive justification of each potential capability utilizing SME expertise to complete a Function Capability Matrix, proposed in this paper as a way to 
document, compile, and synthesize the insights of appropriate SMEs related to each function and its associated capabilities. It should be noted that this matrix only justifies the inclusion or exclusion of functions and capabilities. It does not identify how any might be combined, co-located, or otherwise architecturally arranged.

\section{Function Capability Matrix Description}

A separate Function Capability Matrix is used for each function. Within the matrix, for each capability, a capability description must be entered by the designer. This provides a description of the intended capability in a way to let the designer communicate intent to the SMEs. For instance, for the capability of "two person meetings," the designer may indicate that two persons can meet, facing each other with unobstructed line of sight, with at least six inches separation between the nearest body parts of the two. The SMEs can then provide any pros, cons, or unknowns related to the intended capability, as well as related comments. It should not be blindly assumed that all listed capabilities are important for any long duration habitat. Nor should it be blindly assumed that capabilities can be arbitrarily reduced or eliminated to meet mass, volume, or other targets. There is no substitute for an informed review of each potential capability with the inputs of appropriate SMEs.

\section{A. Living Functions}

\section{Private Habitation}

\section{Purpose}

Private habitation encompasses those functions performed by the crew in isolation from other crew, excluding hygiene and waste functions. NASA-STD-3001 requires private quarters for crew for missions greater than 30 days in duration [5], but does not specifically define the capabilities of private quarters. It also requires private audio and video, which could potentially be co-located with private quarters.

The range of capabilities for private habitation can be expressed in both environmental and operational domains. Environmentally, private quarters can encompass visual, auditory, olfactory, and tactile separation, air temperature and flow control, radiation protection, and lighting control. Operationally, private quarters can include direct window viewing, single person personal computing (including data entry/manipulation, video watching, etc.), physical work surface access, non-sleep rest/relaxation, meditation, stretching, two person meetings, snacking, changing clothes, viewing appearance, video communication, and audio communication.

\section{Examples}

On the International Space Station, private habitation is provided by means of a private crew quarters volume slightly larger than a payload rack. Figure 4 shows an ISS American crew quarters as outfitted for habitation by Astronaut Scott Kelly.

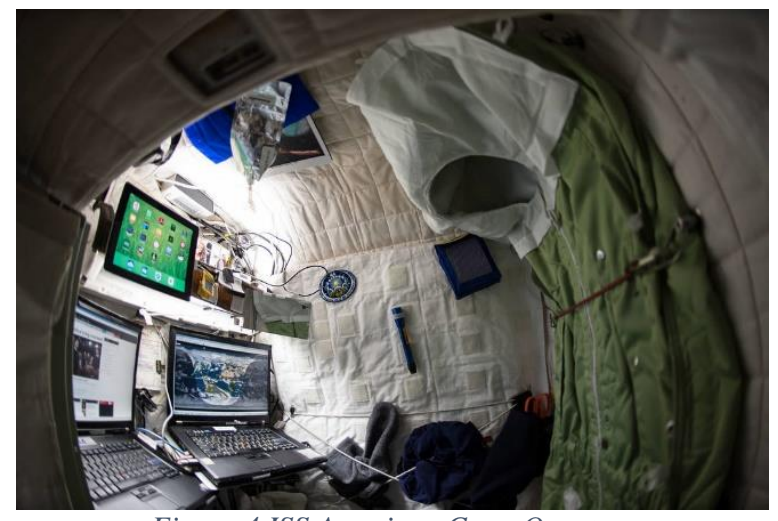

Figure 4 ISS American Crew Quarters

Skylab provided a similarly sized crew quarters, as does the Russian segment of the ISS, as indicated in Fig. 5 and 6 respectively. In general, the three crew quarters designs are roughly similar in volume, though based on visual inspection it appears that the ISS American and Russian crew quarters considered more non-sleeping activities (note the computer configuration), while the Skylab crew quarters appears to have only considered the need to sleep. This may imply a level of design maturity between the 1970s era Skylab and the more modern International Space Station as well as opportunities introduced by the advent of laptop and tablet PC technologies. It is also worth noting that the ISS American crew quarters incorporate radiation protection into the crew quarters structure. This has been a de facto assumed capability of crew quarters in many design studies within the past decade, however it is worth using radiation 
SME knowledge to determine the appropriate approach to radiation protection, which may impact which functions include radiation protection as capabilities. Alternative solutions to lining the crew quarters walls may exist for some habitation scenarios.

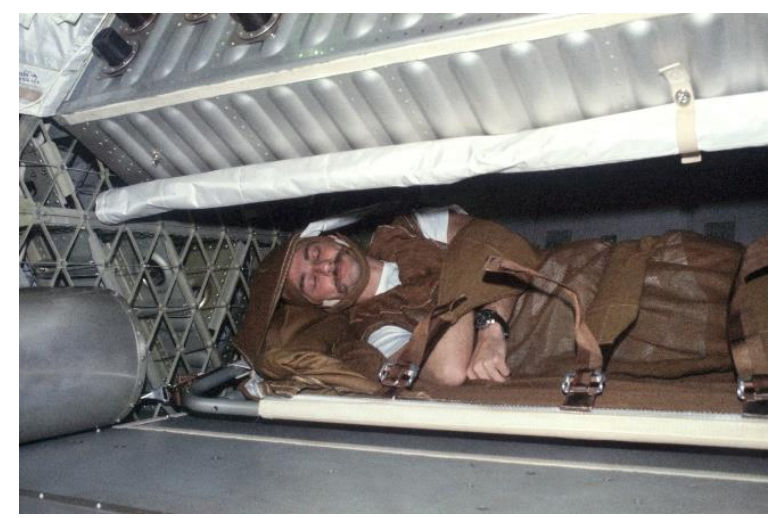

Figure 5 Skylab Crew Quarters

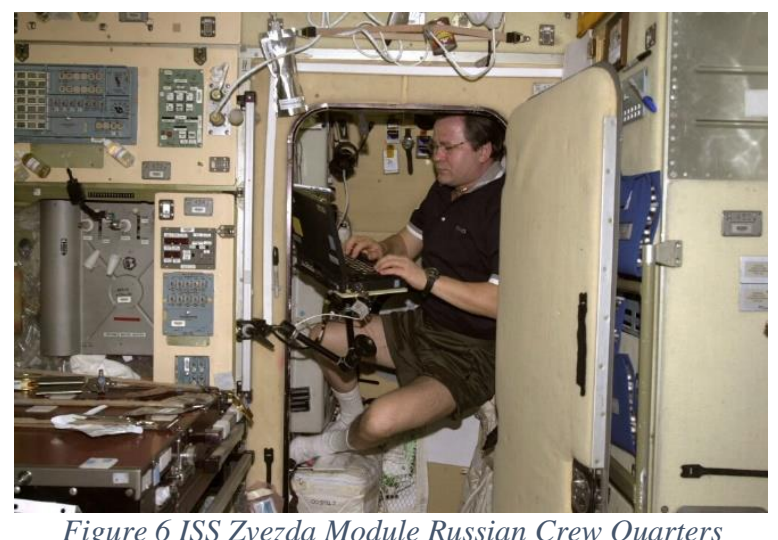

Appropriate SMEs

Avionics, Behavioral Health, Environmental Control and Life Support (ECLS), Human Factors, Logistics, Medical, Mission Control, Astronaut Office, Industrial Design, Architecture, Habitability, Materials, Radiation

\section{Hygiene}

\section{Purpose}

Hygiene includes practices conducive to maintaining health and preventing disease, especially through cleanliness, as well as activities to maintain personal appearance. NASA-STD-3001 requires privacy specifically for body cleansing [5], but does not address whether other hygiene practices should or should not be private. It does require hygiene provisions for each crew member and the capability to sterilize personal hygiene facilities and equipment [5].

Similar to private habitation, hygiene's range of capabilities can also be expressed in terms of environmental and operational domains. Environmentally, hygiene can encompass visual, auditory, olfactory, and tactile separation, air temperature and flow control, and lighting control. Operationally, hygiene can include full body cleaning, facial cleaning, hand cleaning, physical work surface access, viewing appearance, oral hygiene, shaving, hair styling/grooming, finger/toe nail clipping, and skin care.

\section{Examples}

The ISS does not provide a separate, enclosed area for hygiene. Instead it is practiced in a variety of locations such as hair grooming in the aisle of Node 3, as shown in Fig. 7. Anecdotal evidence suggests the crew found the toilet an unacceptable location for hygiene and due to a lack of any other location they perform hygiene activities wherever they can find the best (to them) alternative. Skylab similarly provided relatively little privacy for hygiene, with the notable exception of body hygiene. Skylab developed a zero gravity shower, shown in Fig. 8. Unfortunately, the shower was notoriously burdensome to use and no spacecraft since have attempted showers. 


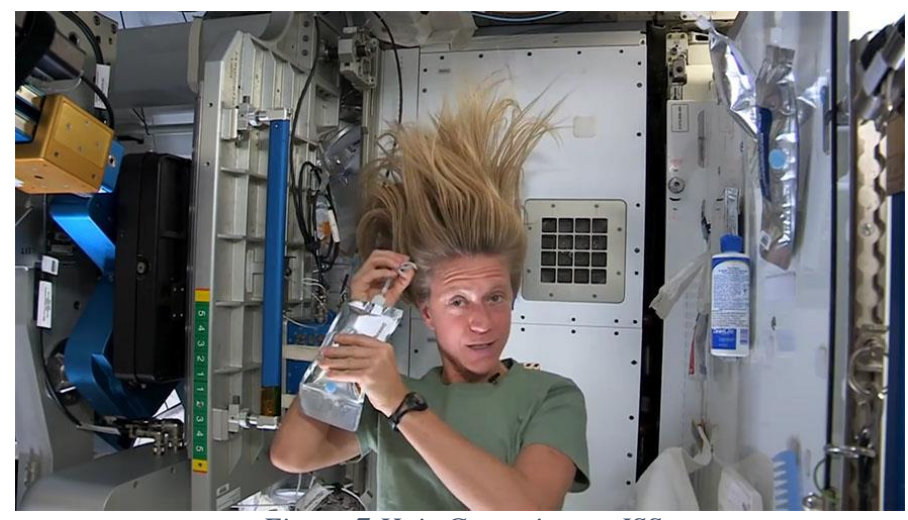

Figure 7 Hair Grooming on ISS

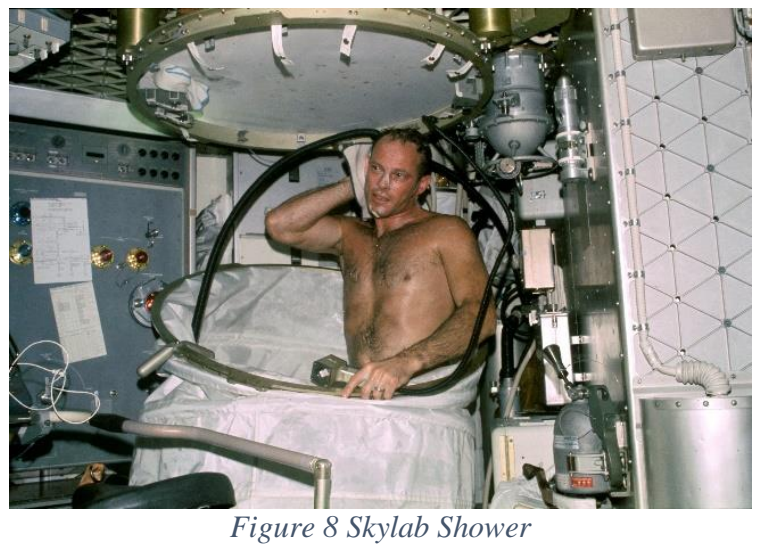

\section{Appropriate SMEs}

Behavioral Health, Environmental Control and Life Support (ECLS), Human Factors, Medical, Astronaut Office, Industrial Design, Architecture, Habitability, Materials

\section{Human Waste Collection}

\section{Purpose}

Human waste collection includes the collection, containment, and disposal of the various wastes generated by the human body including urine, feces, vomitus, and menses. NASA-STD-3001 defines numerous standards related to human waste collection [5].

Human waste collection shares the previously mentioned potential environmental capabilities of visual, auditory, olfactory, and tactile separation, air temperature and flow control, and lighting control. Operationally, human waste collection includes liquid waste collection, solid waste collection, post-waste release private bodily self-inspection and cleaning, hand cleaning, and facility/equipment cleaning/sanitation and maintenance.

\section{Examples}

Both the Space Shuttle Orbiter and the ISS provided human waste collection volumes, as shown in Fig. 9 and 10 respectively. The shuttle Waste Collection System (WCS) used a combination of a hard door and curtains to obtain limited visual privacy. (There were gaps in the curtains when deployed.) The ISS Waste and Hygiene Compartment (WHC) was initially placed on the Destiny US Laboratory module, but later moved to Node 3 . Similar to the shuttle WCS, the WHC uses curtains to provide visual privacy. 


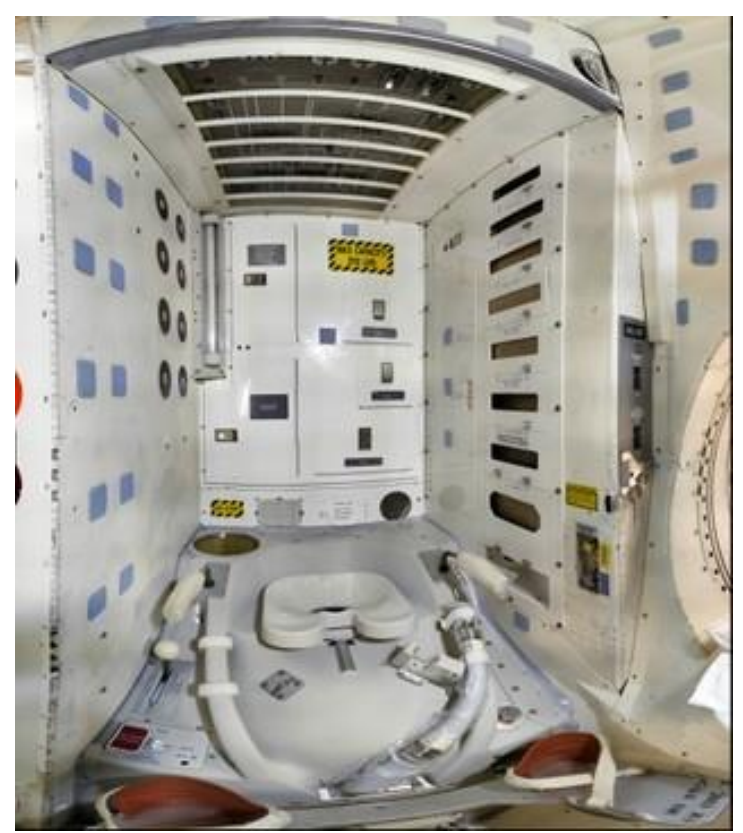

Figure 9 Shuttle Orbiter Waste Collection System

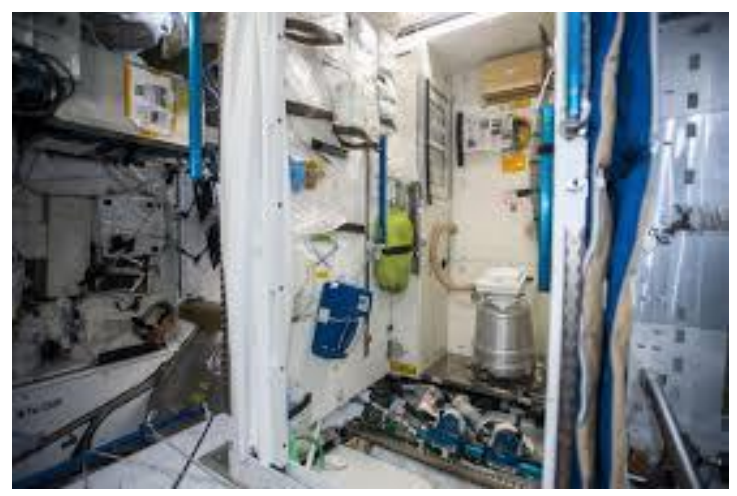

Figure 10 ISS Waste and Hygiene Compartment

\section{Appropriate SMEs}

Behavioral Health, Environmental Control and Life Support (ECLS), Human Factors, Medical, Astronaut Office, Industrial Design, Architecture, Habitability

\section{Meal Preparation}

\section{Purpose}

Meal preparation includes the preparation and allocation of food to the crew for consumption, potentially including both prepackaged and fresh food. NASA-STD-3001 defines relevant standards related to food and nutrition [5].

Meal preparation includes the environmental capabilities of air temperature and flow control and lighting control. Operational capabilities for meal preparation can be divided into basic and advanced capabilities. Basic operational capabilities include rehydration, food warming, food item sorting, utensil and food equipment hygiene, and facility/equipment cleaning/sanitation and maintenance. Advanced operational capabilities include plant growth, plant harvesting, plant processing, aquatic animal growth, small animal growth, meat processing, food packaging, food chilling, and food cooking.

\section{Examples}

The space shuttle's galley is its workstation devoted to meal preparation. The shuttle galley, shown in in Fig. 11, contained no dedicated environmental capabilities and only the basic operational capabilities of rehydration

10

American Institute of Aeronautics and Astronautics 
and food warming. Sorting, utensil and food equipment hygiene, trash stowage, and facility/equipment cleaning were performed with other resources onboard the vehicle.

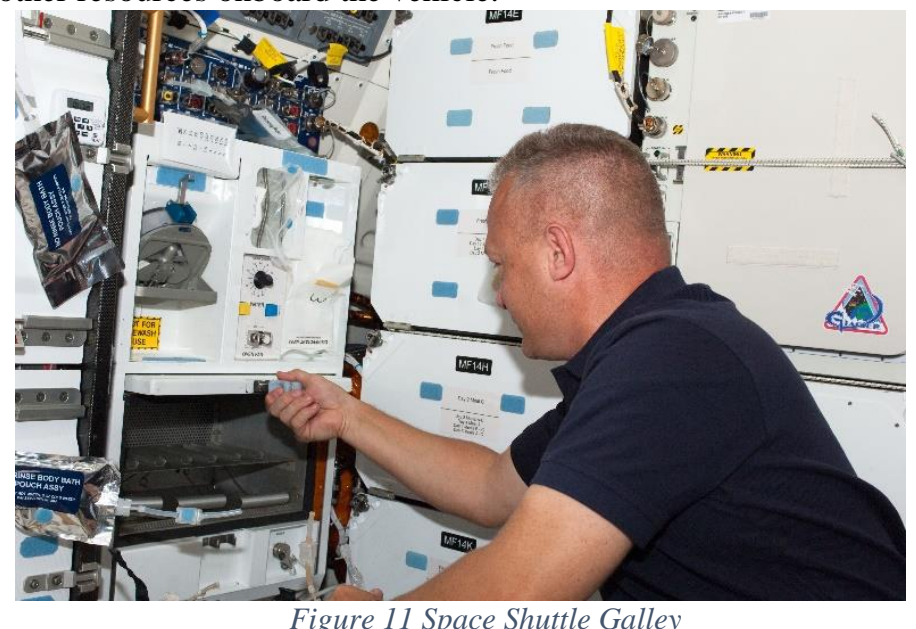

The US segment of the ISS has a galley, shown in Fig. 12, that is a slightly upgraded version of the shuttle galley. In addition to the shuttle's capabilities, the ISS also adds the advanced operational capabilities of plant growth and plant harvesting with plant chambers located separately from the galley, shown in Fig. 13. The plants do not replace the prepackaged food, but provide only a small supplement.
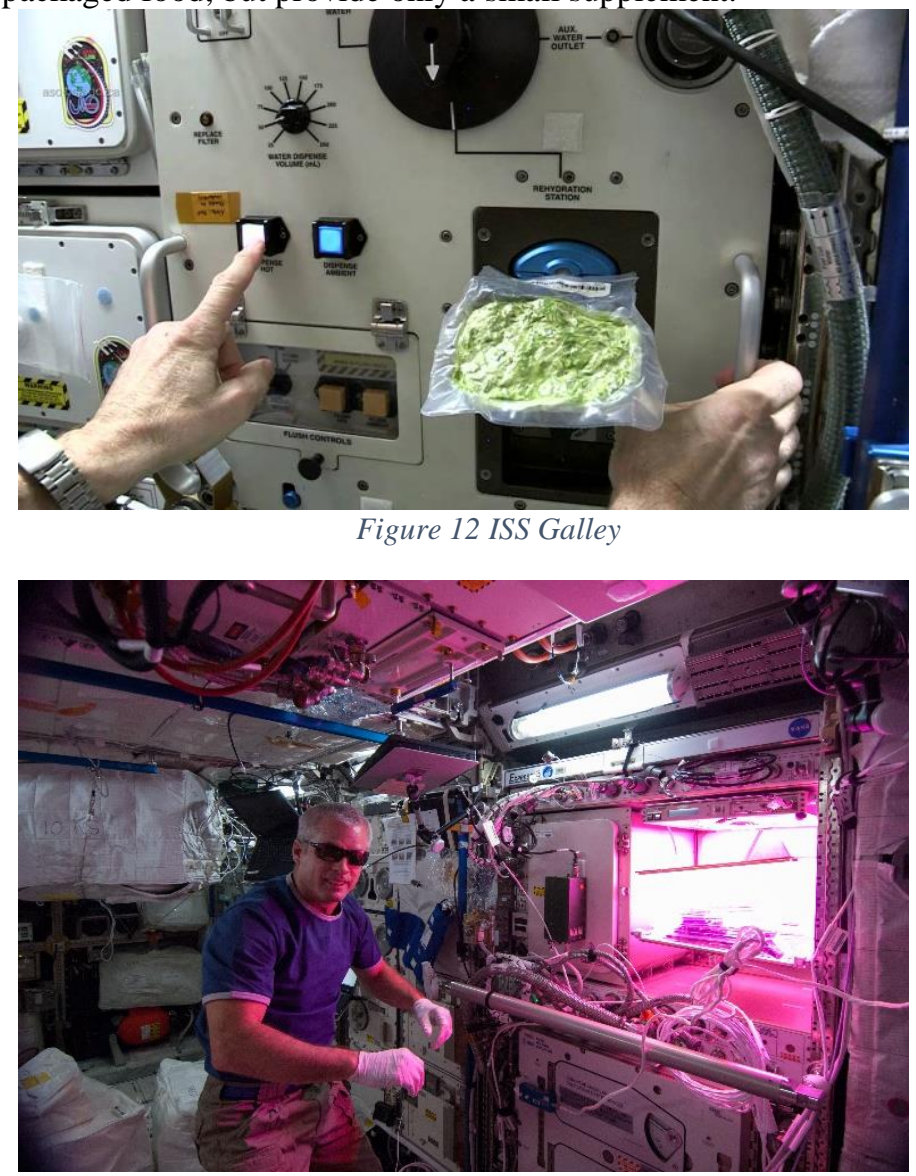

Figure 13 ISS Plant Growth Chamber 


\section{Appropriate SMEs}

Behavioral Health, Crew Systems, Human Factors, Logistics, Medical, Food Science/Nutrition, Astronaut Office, Industrial Design, Architecture, Habitability

\section{Meal Consumption}

\section{Purpose}

Meal consumption includes daily consumption of food and beverage, including both scheduled meals and snacks. NASA-STD-3001 requires that crew be able to dine together [5].

Meal consumption includes the environmental capabilities of air temperature and flow control and lighting control. Operational capabilities for meal consumption include full crew accommodation/restraint, dining surface, accessible mounting of condiments, direct window viewing, audio display, and video display.

\section{Examples}

The ISS wardroom, shown in Fig. 14, is a deployable table that can accommodate pre-positioned condiments. Depending on ISS crew size (has varied over history of ISS expeditions), the wardroom table is often able to accommodate the entire crew.

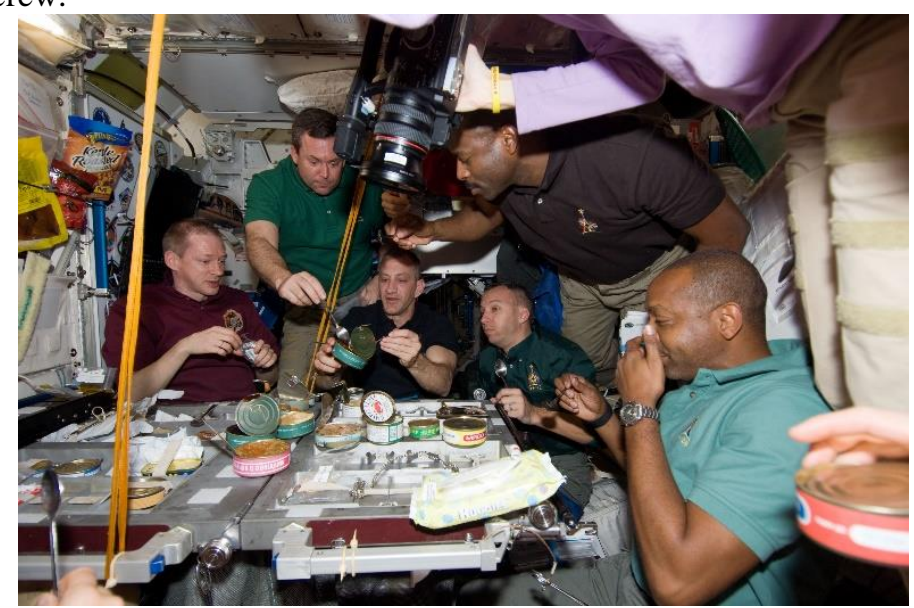

Figure 14 ISS Wardroom

\section{Appropriate SMEs}

Behavioral Health, Crew Systems, Human Factors, Medical, Food Science/Nutrition, Astronaut Office, Industrial Design, Architecture, Habitability

\section{Group Socialization and Recreation}

\section{Purpose}

Group Socialization and Recreation includes interaction of two or more crew members, up to and including the entire crew complement. NASA-STD-3001 only requires that there must be recreational capabilities for the crew to maintain behavioral and psychological health [5], but does not define what those capabilities might be. This paper recommends that group activities should be part of the solution set.

Group Socialiazation and Recreation environmental capabilities include temperature and flow control and lighting control. Operational capabilities include direct window viewing, video/movie viewing, computer based games, tabletop games, athletic games, and artistic/creative recreation.

\section{Examples}

Skylab did not contain dedicated recreational facilities, but because of the large, open volumes in the spacecraft the astronauts were able to improvise. Figure 15 shows a Skylab astronaut running (for fun, not for exercise) on top of the stowage lockers that ringed the Orbital Workshop (the largest pressurized section of Skylab). NASA video footage shows entire three-person crews running together on top of these lockers, playing gymnastics around them, and tumbling in other ways through this open space. Figure 16 shows astronauts aboard the International Space Station playing with a soccer ball. 


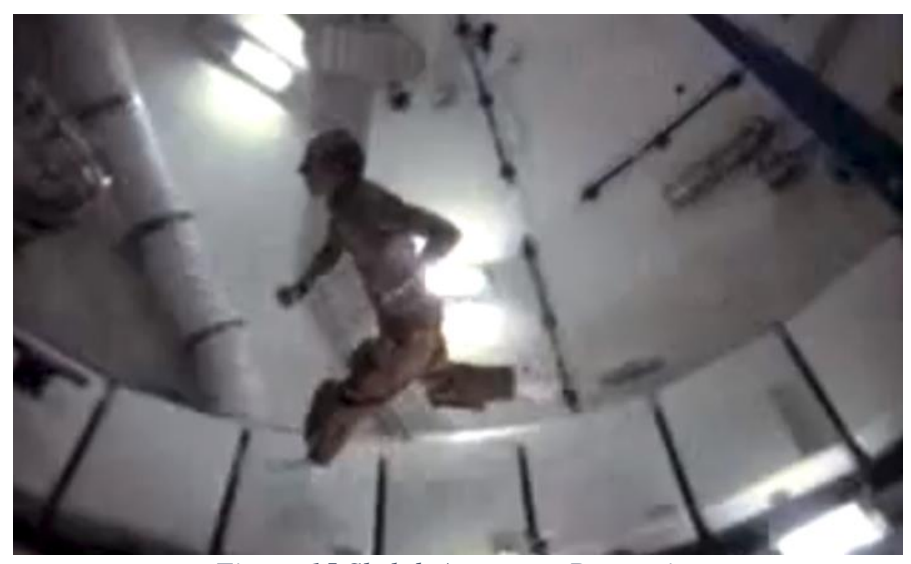

Figure 15 Skylab Astronaut Recreation

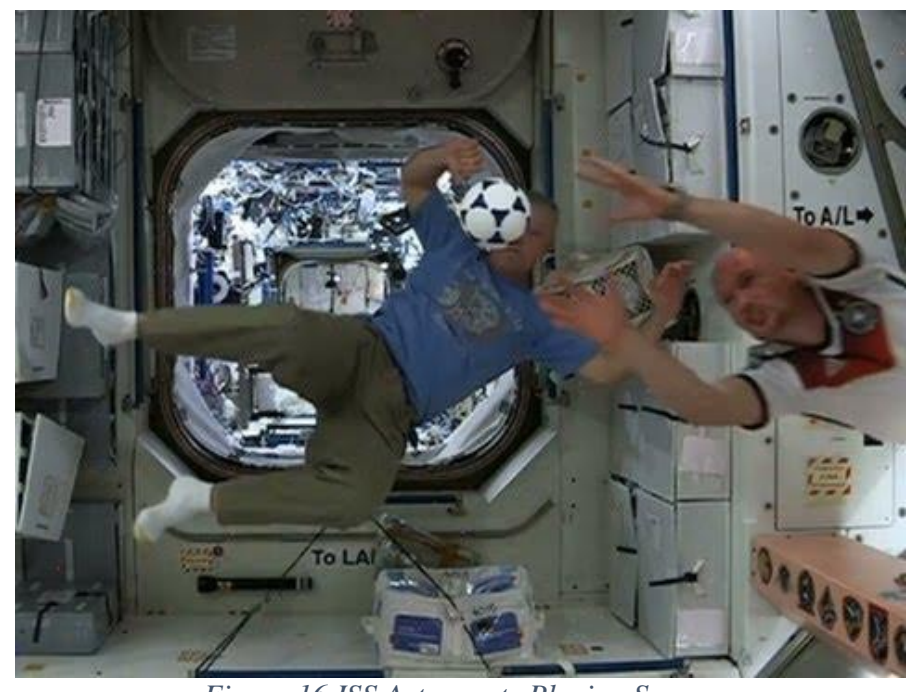

Figure 16 ISS Astronauts Playing Soccer

\section{Appropriate SMEs}

Behavioral Health, Crew Systems, ECLSS, GNC, Human Factors, Astronaut Office, Industrial Design, Architecture, Habitability, Structures

\section{Exercise}

\section{Purpose}

Exercise is required to counteract the adverse physiological effects of reduced gravity and must provide aerobic conditioning, muscular conditioning, counteract bone loss, maintain sensorimotor capability, and support psychological well-being. Some exercise protocols are also involved in treatment of decompression sickness. NASA-STD-3001 contains multiple requirements for spacecraft exercise capabilities as well as crew bone, muscle, sensory-motor, and cardiovascular standards for crew health [5].

Exercise capabilities can be grouped in terms of environmental, physiological, and operational capabilities. Environmentally, exercise can encompass visual, auditory, olfactory, and tactile separation, air temperature and flow control, and lighting control. Physiologically, exercise can include aerobic, resistive, bone loading, and sensorimotor. Operationally, exercise can include sweat barricade, audio display, video display, and data entry.

\section{Examples}

The International Space Station uses three exercise devices for US astronauts, a cycle ergometer (CEVIS), a treadmill (T2), and an Advanced Resistive Exercise Device (ARED). ARED, shown in Fig. 17, is one of the largest exercise devices ever flown in space and work is currently underway to develop new resistive exercise devices with lower mass and volume requirements that can still meet astronaut physiological needs. Some of these 
new devices are likely to see service on either the Orion capsule or the Gateway spacecraft, both of which are relatively short duration vehicles. However, as of the time of this research, the ARED is the only resistive exercise device that meets US astronaut requirements for long duration spaceflight.

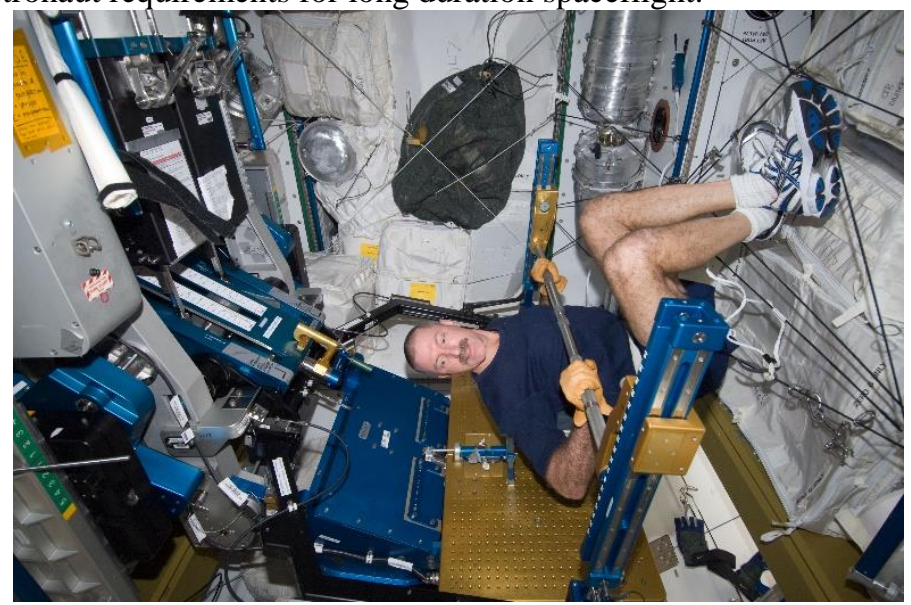

Figure 17 ISS Advanced Resistive Exercise Device

\section{Appropriate SMEs}

Behavioral Health, Countermeasures, ECLSS, Human Factors, Astronaut Office, Industrial Design, Architecture, Habitability, Structures

\section{Medical Operations}

\section{Purpose}

An onboard medical capability is necessary to provide health care for the crew, inclusive of preventative medicine, emergency medicine, and medical research. NASA-STD-3001 defines numerous medical requirements and specifies a level of care based on a generalized type of mission and location [5].

Medical capabilities can be described in terms of environmental, operational, and treatment capabilities. Environmental capabilities can encompass visual, auditory, olfactory, tactile, and data separation, air temperature and flow control, and lighting control. Operational capabilities may include audio communication, video communication, private telemedicine, computer data entry/manipulation, and two person meetings. Treatment capabilities may include space motion sickness, first aid, anaphylaxis response, clinical diagnostics, ambulatory care, trauma care, medical imaging, dental care, autonomous advanced life support, and basic surgical care.

\section{Examples}

There is no dedicated medical facility on the International Space Station. Instead, medical supplies are stored in stowage bags and medical treatment is provided in any location selected by the crew. Figure 18 shows medical equipment deployed to perform an ultrasound in the ISS Columbus laboratory module. Some exploration conceptual designs have experimented with dedicated medical facilities. The NASA Habitat Demonstration Unit (also known as Human Exploration Research Analog, or HERA) is an analog spacecraft mockup that includes a Medical Operations Workstation, shown in Fig. 19. Not visible in figure 19 is a deployable surgical bed that stows under the workstation desk/work surface. 

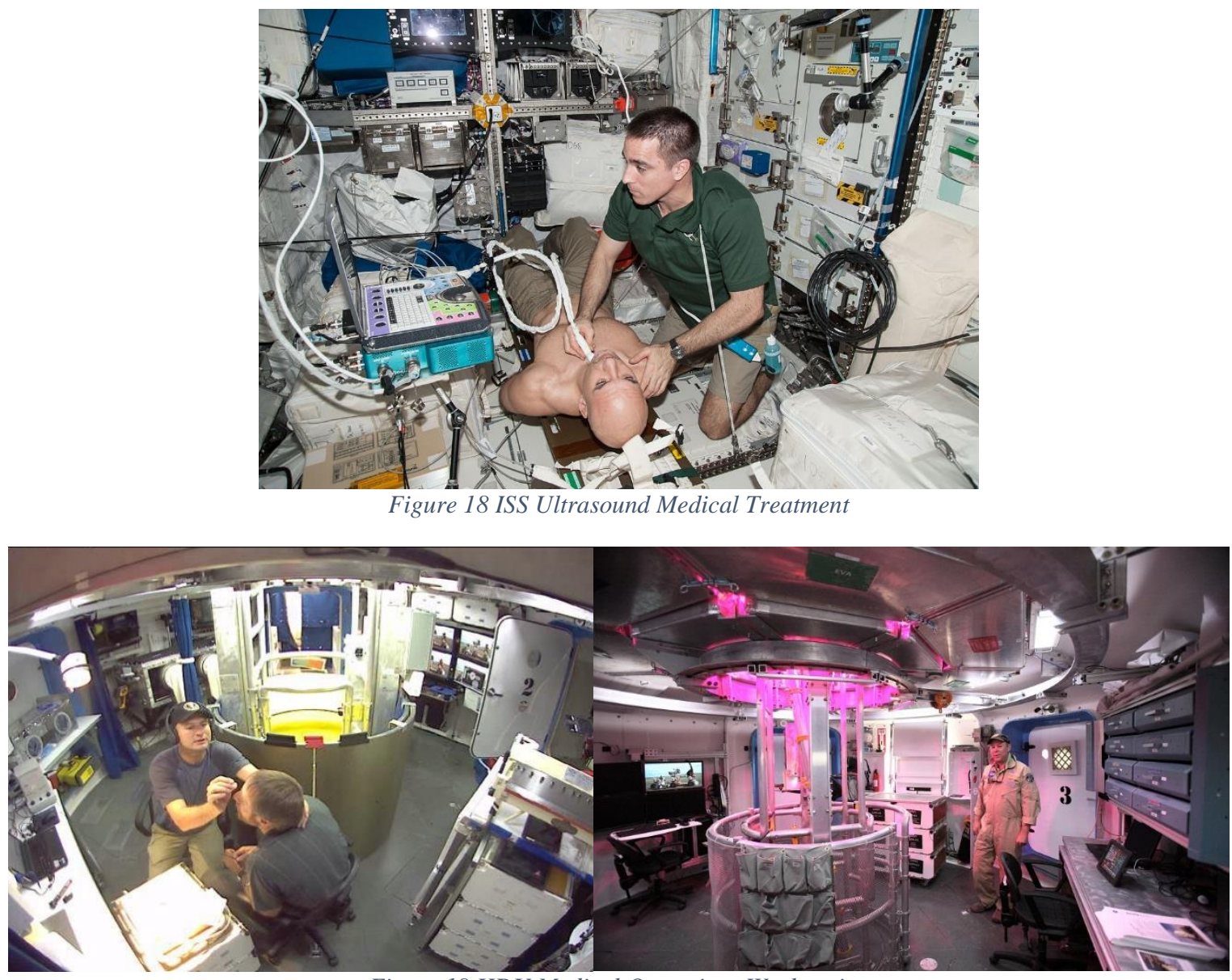

Figure 19 HDU Medical Operations Workstation

Appropriate SMEs

Medical, Human Factors, Astronaut Office, Industrial Design, Architecture, Habitability

B. Working Functions

9. Scientific Research

Purpose

Scientific research is one of the primary purpose of human spaceflight. Humans travel to destinations in space, whether orbital or surface, in order to understand the destination environment, understand Earth or the rest of the universe from the destination environment, search for native life in the destination environment, or understand how to extend terrestrial life to the destination environment. NASA-STD-3001 contains numerous standards relating to the configuration of scientific workstations, especially as related to displays, controls, and information management [5].

Scientific research capabilities can be grouped in environmental, operational, and domain capabilities. Environmental capabilities can include encompass visual, auditory, and data separation, air temperature and flow control, and lighting control. Operational capabilities encompass computer display and control interface (including displays, data entry devices, and hand controllers), physical work surface access, telescience, direct window viewing, video communication, and audio communication. Potential domain capabilities include space medicine, human factors and habitability, food \& nutrition, human health countermeasures, space radiation, environmental health, cellular and molecular biology, botany, animal science, entomology, mammalogy, herpetology, ornithology, ethology, zoography, biotechnology, genetics, mycology, chemistry, acoustics, cryogenics, combustion, fluid science, materials science, physics, optics, astronomy/astrophysics, heliophysics, meteorology, planetary science, in-situ resource utilization, robotics, and engineering/technology prototyping and testing.

15

American Institute of Aeronautics and Astronautics 


\section{Examples}

The International Space Station contains multiple modules devoted primarily to scientific research. The US Operational Segment (including the US Destiny lab module, Japanese Kibo lab module, and European Columbus lab module utilize a rack structure where racks of a common dimension are outfitted with a variety of scientific instruments and payloads, as shown in Fig. 20. By comparison, NASA experimented with the design of a dedicated geology workstation for a lunar outpost and conducted field testing of it in the Habitation Demonstration Unit, shown in Fig. 21.

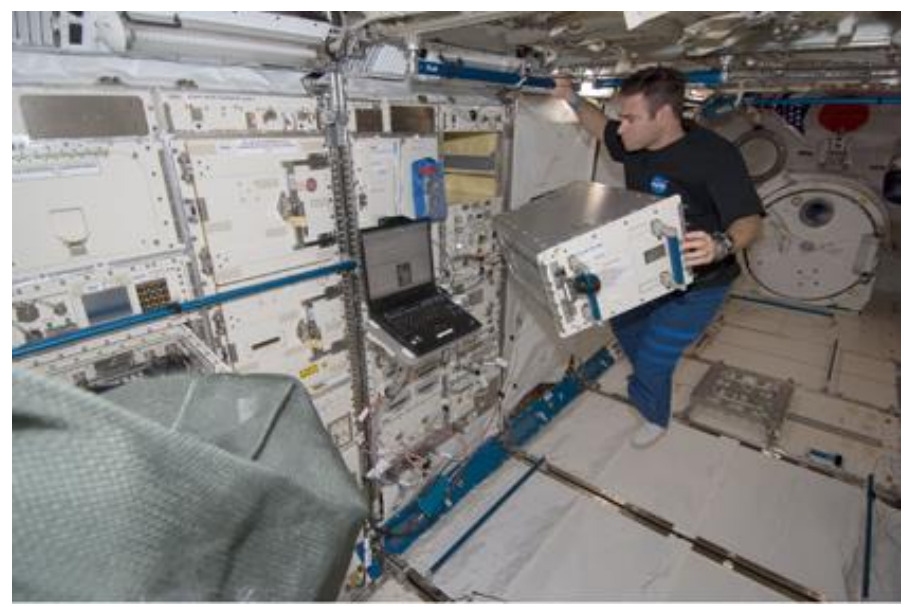

Figure 20 Astronaut Installing Payload in a Kibo Science Module Rack

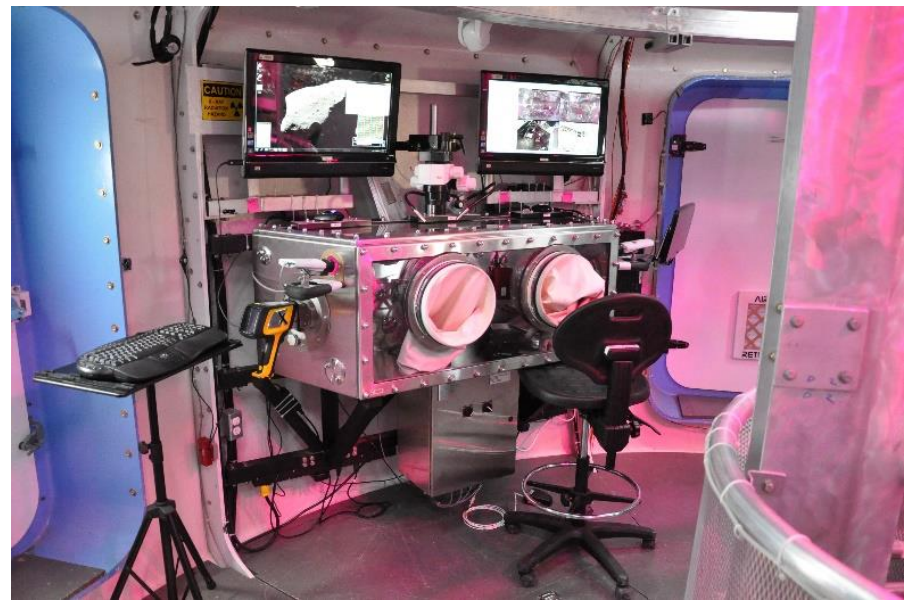

Figure 21 HDU Geology Laboratory

\section{Appropriate SMEs}

Human Factors, Astronaut Office, Industrial Design, Architecture, Habitability, Life Science, Physical Science, Earth/Space Science, Engineering/Technology Testing, ISRU

\section{EVA Operations}

\section{Purpose}

Extra-Vehicular Activity (EVA) refers generally to the ability of humans, cargo, or robots to exit the spacecraft to conduct tasks or to be exposed to the external environment. EVAs may be performed by crew or robots to support nominal vehicle operations, conduct mission science, or mitigate contingencies. Cargo or payloads may require EVA for scientific research or to support nominal or contingency operations. Any EVA capability requires some form of airlock, suitlock, suitport or comparable transfer system to move people or equipment between the spacecraft internal environment and the exterior. Relevant design guidance is contained in EVA-EXP-0031, EVA Office Extracurricular Activity (EVA) Airlocks and Alternate Ingress/Egress Methods Document and EVA-EXP0035, EVA Office Exploration EVA System Compatibility [6, 7].

16

American Institute of Aeronautics and Astronautics 
EVA capabilities can be grouped in environmental and operational capabilities. Environmental capabilities can include depressurization, repressurization, hyperbaric isolation, hypobaric isolation, air temperature and flow control, and lighting control. Operational capabilities encompass EVA suit donning and doffing, crew ingress/egress, robot ingress/egress, subsystem or payload ingress/egress, suit servicing, suit repair, suit component testing, IVA support of EVA, computer display and control interface, video communication, and audio communication.

\section{Examples}

The International Space Station US segment uses a traditional airlock, named Quest, separated into a crew lock (the smaller portion that depressurizes) and an equipment lock (a larger volume, for donning/doffing and suit/equipment stowage. Figure 22 shows the ISS Quest airlock during its initial delivery to the International Space Station, while Fig. 23 shows a view of the interior of Quest once filled with EVA items. The Multi-Mission Space Exploration Vehicle (MMSEV) foregoes the airlock and instead uses two suit ports, specially designed bulkheads that allow a suit to mate to the spacecraft bulkhead. An astronaut can transition from spacecraft to suit by climbing through a hatch on the back of the suit. Figure 24 shows the suit ports on the back of the Lunar Electric Rover (LER) / MMSEV first generation prototype.

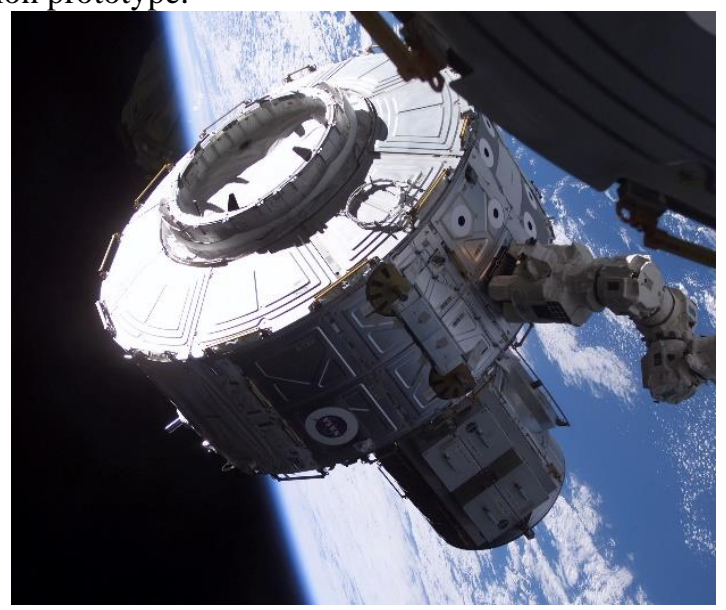

Figure 22 ISS Quest Airlock

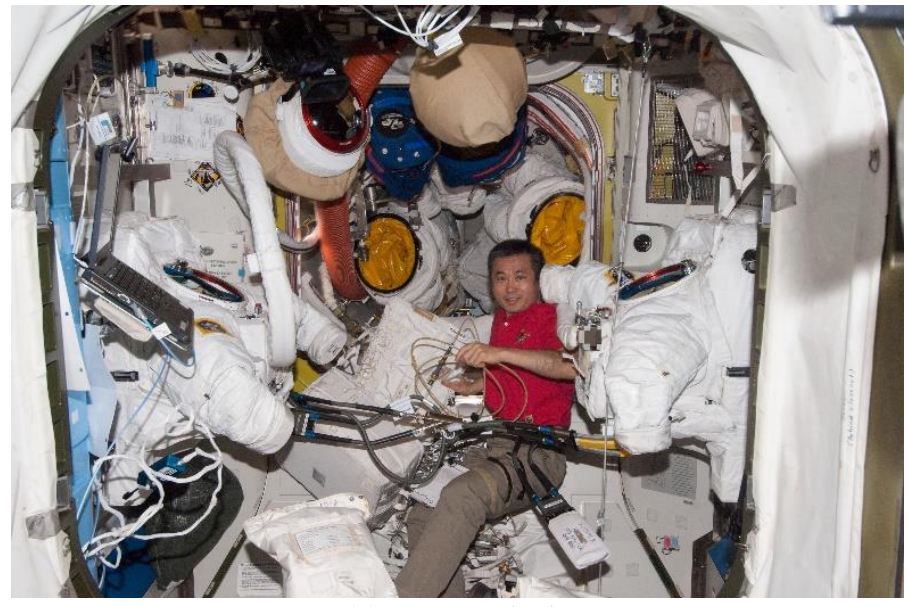

Figure 23 Quest Airlock Interior 


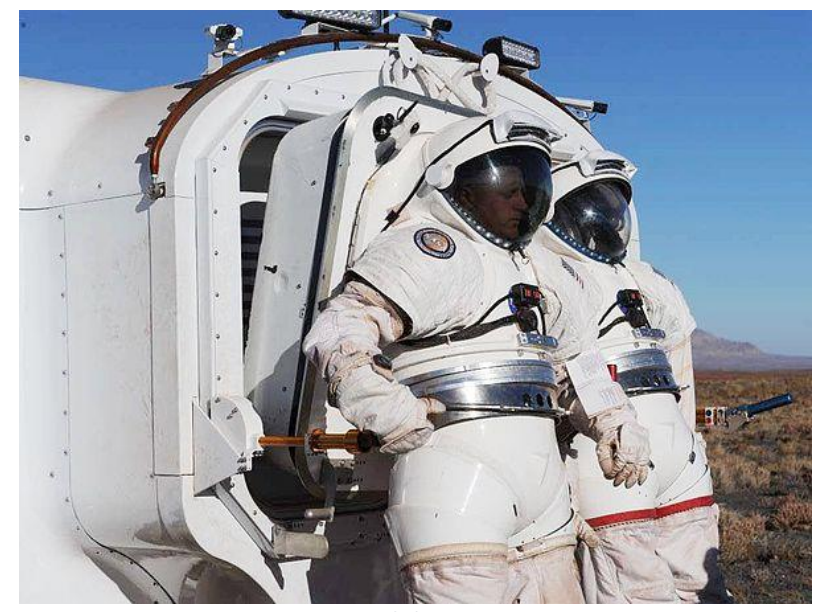

Figure 24 Suit Port

\section{Appropriate SMEs}

Human Factors, Astronaut Office, Industrial Design, Architecture, Habitability, EVA, Medical, In-Flight Maintenance, Life Science, Physical Science, Earth/Space Science, Engineering/Technology Testing, ISRU

\section{Spacecraft Monitoring and Commanding}

\section{Purpose}

Spacecraft monitoring and commanding refers to the crew's ability to operate their spacecraft. For dynamic flight vehicles this may include manually flying the vehicle, but even for stationary spacecraft such as a planetary surface outpost there is still monitoring and commanding by means of accessing and controlling the outpost subsystems. Monitoring and commanding may also include remote control of other spacecraft. Relevant standards in NASA-STD-3001 primarily relate to displays, controls, and information management [5].

Spacecraft monitoring and commanding capabilities can be expressed in terms of environmental and operational capabilities. Environmental capabilities can include encompass visual, auditory, and data separation, air temperature and flow control, and lighting control. Operational capabilities encompass piloting, teleoperation, computer display and control interface, subsystem manual display and control interface, direct window viewing, video communication, and audio communication.

\section{Examples}

In the space shuttle orbiter, spacecraft monitoring and commanding could only be performed from the flight deck. The majority of shuttle systems were monitored and commanded from the commander and pilot seats. The commander's seat is pictured in Fig. 25. The International Space Station, by comparison, was less reliant on fixed workstations with the ability to access and command vehicle subsystems from any workstation. However, commanding the ISS robot arm to perform servicing and logistics operations still required a configured work area, which was initially located in the US Laboratory, shown in Fig. 26, but later relocated to the Cupola, shown in Fig. 27. 


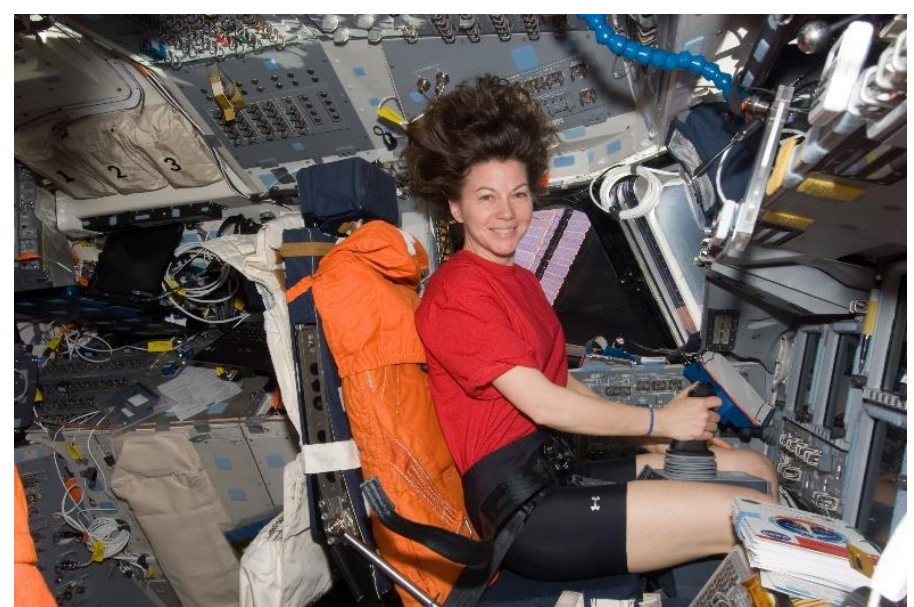

Figure 25 Space Shuttle Flight Deck, Commander's Seat

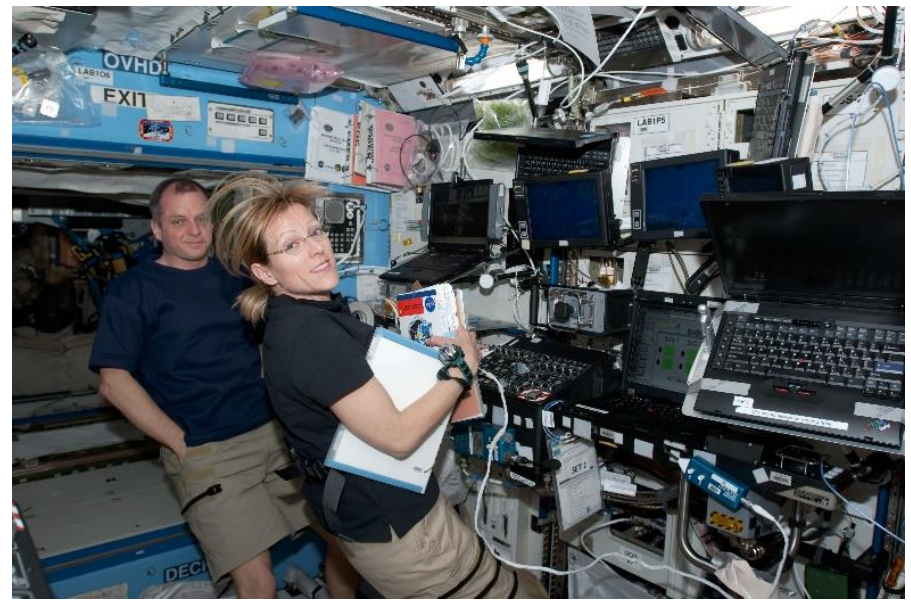

Figure 26 ISS Robotics Workstation in the US Laboratory Module

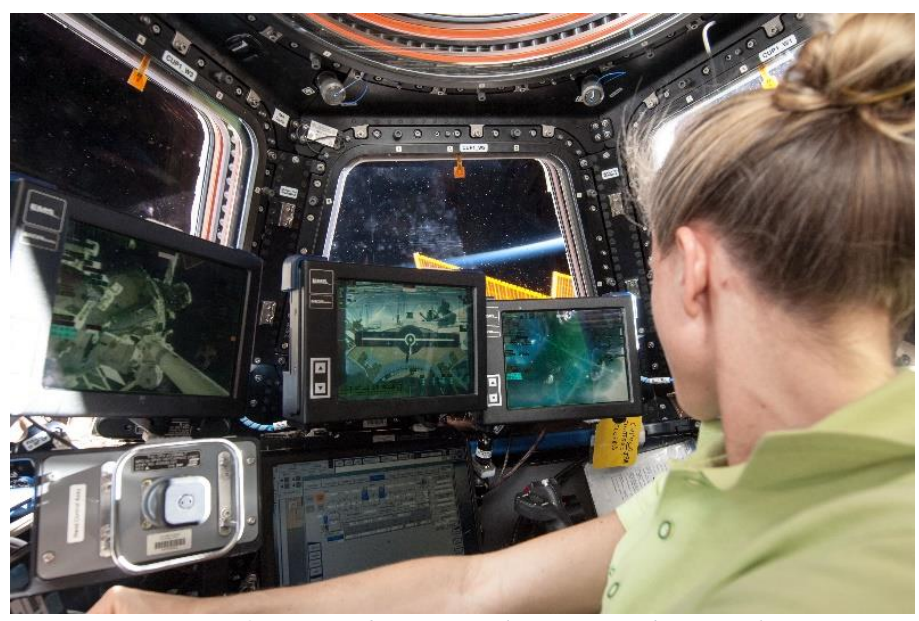

Figure 27 ISS Robotics Workstation in the Cupola

\section{Appropriate SMEs}

Human Factors, Human Interfaces, Astronaut Office, Industrial Design, Architecture, Habitability, Avionics 


\section{Mission Planning}

\section{Purpose}

Mission planning includes both group and individual planning, as well as planning in consultation with the ground and autonomous planning. It is inclusive of high level daily timelines, higher level listing of mission goals or activities, execution planning for individual procedures, and even staging of materials to execute a task. NASASTD-3001 includes standards relevant to mission planning, particularly with respect to information management [5].

Spacecraft monitoring and commanding capabilities can be expressed in terms of environmental and operational capabilities. Environmental capabilities can include encompass visual, auditory, and data separation, air temperature and flow control, and lighting control. Operational capabilities encompass physical work surface access, computer display and control interface, video communication, and audio communication.

\section{Examples}

The NASA Habitat Demonstration Unit included two locations that could be used by crew for mission planning. The laboratory deck included a teleoperations workstation, shown in Fig. 28 (left), that included teleconferencing capability. Test crews could gather around this workstation to engage in video conferences with mission control. The habitation deck included a wardroom, shown in Fig. 28 (right), where crew could gather collectively or as a subset to work through group planning activity. The wardroom table provided sufficient space to mount their laptops and a projector (not visible in figure) projected onto a screen to share data or video.

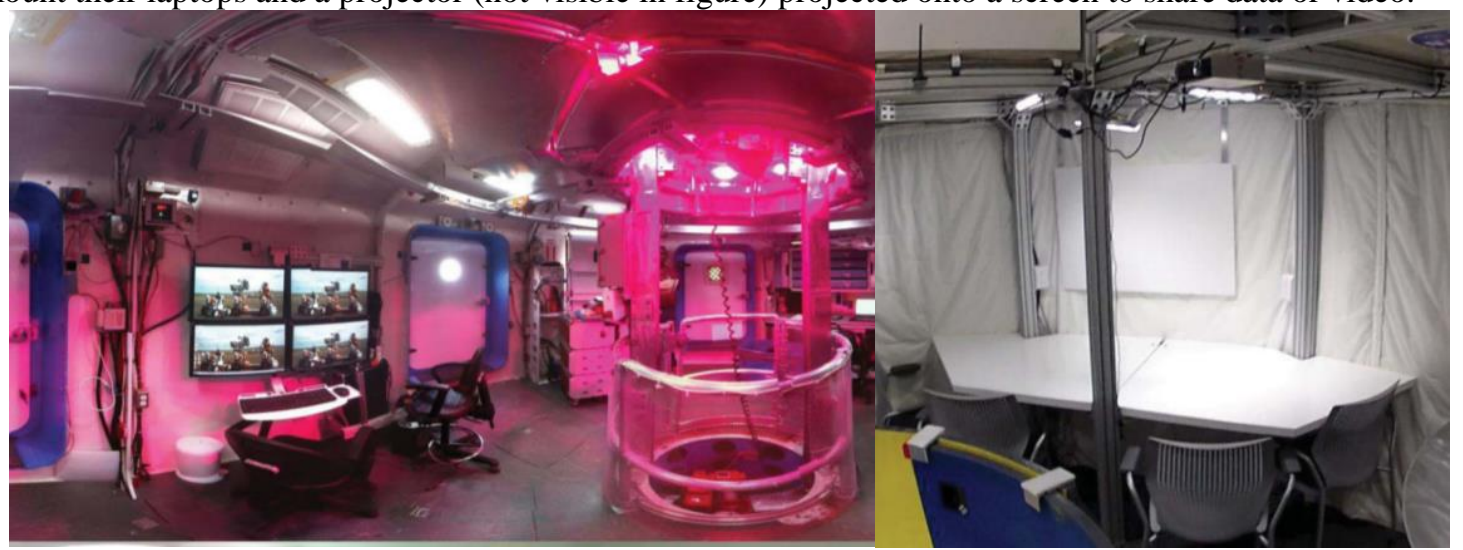

Figure 28 HDU Mission Planning Capabilities

\section{Appropriate SMEs}

Human Factors, Human Interfaces, Astronaut Office, Industrial Design, Architecture, Habitability, Avionics, Crew Scheduling / Flight Activities

\section{Maintenance and Fabrication \\ Purpose}

Maintenance and Fabrication includes nominal, scheduled, and contingency operations to sustain the proper functioning of spacecraft and associated systems, and includes the design and production of systems not launched in or delivered to the spacecraft. NASA-STD-3001 contains standards relevant to maintenance and the design of both hardware to be maintenance and facilities to perform maintenance [5].

Capabilities of this function may be categorized as environmental and operational capabilities. Environmental capabilities may include visual separation, auditory separation, air temperature and flow control, lighting control, dust/particle/fume mitigation, debris capture, and air filtration. Operational capabilities may include computer display and control interface, physical work surface access, telemaintenance, video communication, audio communication, material handling, component sterilization, component isolation, housekeeping, soldering, brazing, welding, 3D printing, CNC fabrication, material drilling, material cutting, material rolling and bending, material fastening, thermoplastic forming, soft goods sewing, soft goods cutting, soft goods patching, surface bonding, materials analysis, electronics analysis, component testing, CAD modeling, and software coding.

\section{Examples}

The Habitat Demonstration Unit includes a fixed workstation specifically designed to support maintenance activity. Additionally, a mobile stowage locker can also be used as a maintenance work surface. Figure 29 shows 20 
both locations in use during a field test. The crew member in the foreground is disassembling a transmission from a lunar rover prototype, a representative task for a maintenance capability in a surface outpost. The International Space Station carries a wide variety of maintenance tools and has recently begun to fly 3D printing capability. Figure 30 shows a part 3D printed aboard ISS as a technology demonstration.

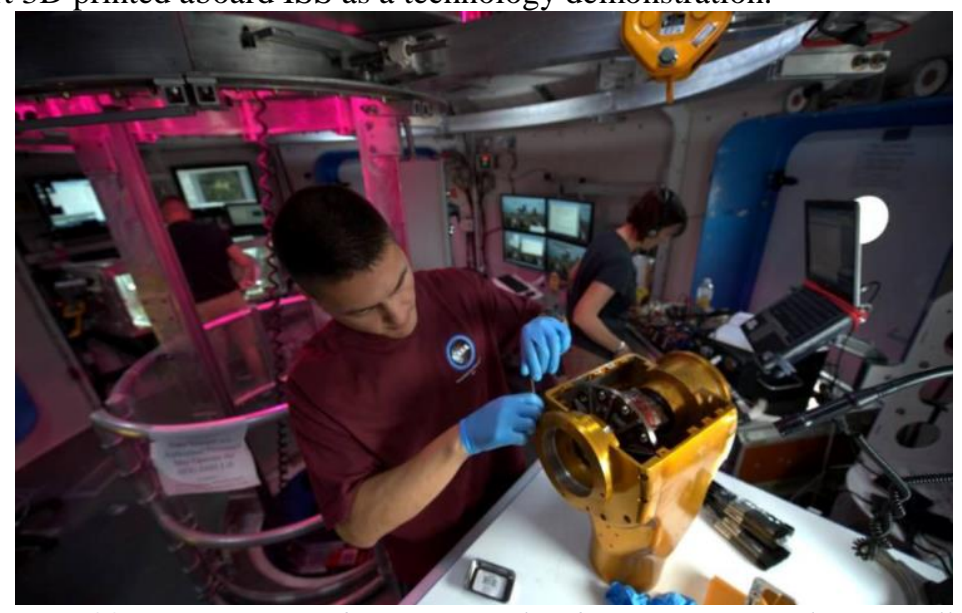

Figure 29 HDU Crew Conduct Two Unrelated Maintenance Tasks in Parallel

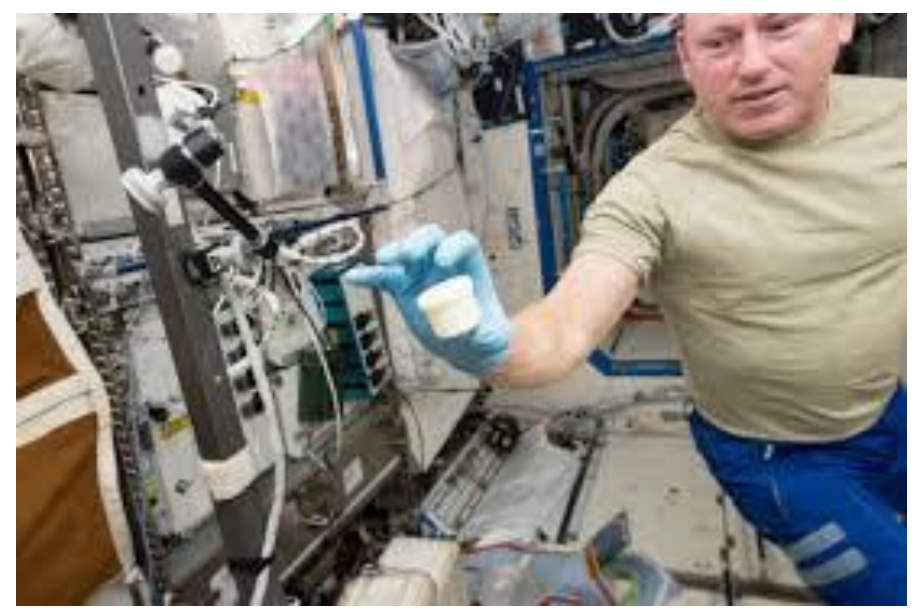

Figure 303 D Printed Part Aboard the ISS

\section{Appropriate SMEs}

Human Factors, Human Interfaces, Astronaut Office, Industrial Design, Architecture, Habitability, In-Flight Maintenance

\section{Logistics}

\section{Purpose}

Logistics includes the containment, transfer, and management of all cargo items contained within the spacecraft, inclusive of trash and waste items generated onboard or transferred aboard from other vehicles or systems. NASA-STD-3001 contains numerous standards related to stowage, inventory management, and trash management [5].

Logistics capabilities may be grouped into categories of environmental, operational, containment, transfer, and management. Environmental capabilities may include air temperature and flow control, lighting control, and stowage temperature control. Operational logistics capabilities include computer display and control interface and physical work surface access. Logistics containment capabilities are inclusive of bulk stowage, temporary stowage, workstation integrated stowage, small item containment, dry trash stowage, wet trash stowage, biologically active trash stowage, human waste stowage, and toxic trash stowage. Transfer capabilities include 
robotic logistics transfer and bulk logistics transfer. Finally, logistics management capabilities include position tracking and inventory management.

\section{Examples}

Logistics aboard the International Space Station includes stowage contained in racks, but the onboard stowage has greatly exceeded the capacity of the stowage racks and includes loose items tied down throughout the station, as shown in Fig. 31. Stowage is delivered via a variety of government and commercial spacecraft, with a former Multi-Purpose Logistics Module (MPLM) now permanently docked to the space station. A variety of inventory management technologies have been utilized on the space station, with outdated bar code readers now being gradually replaced by radio frequency identification (RFID) technology. Anecdotal crew comments have indicated that because of the volume of ISS and the large number of stowed items, some hardware has been lost on the station, in some cases with the item missing for years before being found again. There may be permanently lost items that will never be found.

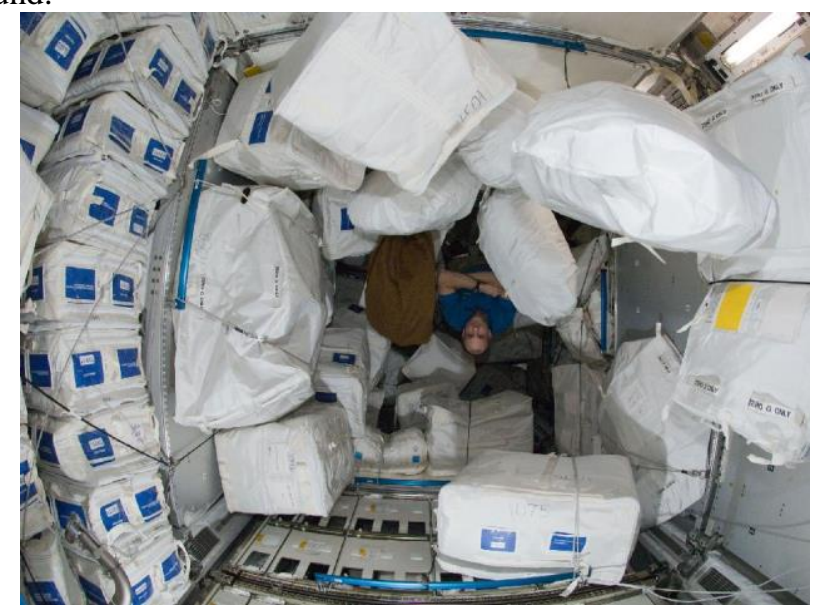

Figure 31 Stowage Onboard the International Space Station

\section{Appropriate SMEs}

Human Factors, Human Interfaces, Astronaut Office, Industrial Design, Architecture, Habitability, Flight Crew Equipment, Logistics, Avionics

\section{Function Capability Matrix Completion}

An example Function Capability Matrix is shown in Table 1 for the function of Private Habitation for a notional lunar outpost with a five-year crew mission. It is shown at the point where the designer has completed the capability descriptions and it is ready to be distributed to SMEs for feedback.

Table 1 Example Function Capability Matrix

Function Capability Matrix - Five-Year Lunar Outpost Private Habitation

\begin{tabular}{|l|l|l|l|l|}
\hline Capability & $\begin{array}{l}\text { Capability Description } \\
\text { (completed by designer) }\end{array}$ & $\begin{array}{l}\text { Pros (to be } \\
\text { completed } \\
\text { by SMEs) }\end{array}$ & $\begin{array}{l}\text { Cons } \text { to be } \\
\text { completed } \\
\text { by SMEs) }\end{array}$ & $\begin{array}{l}\text { Comments and } \\
\text { Unknowns (to } \\
\text { be completed by } \\
\text { SMEs) }\end{array}$ \\
\hline Visual separation & Fully opaque with no light leaks & & & \\
\hline Auditory separation & STC rating 50 or greater & & & \\
\hline Olfactory separation & Filters in air ducts & & & \\
\hline Tactile separation & $\begin{array}{l}\text { Visual barrier is a solid wall, } \\
\text { including a hinged door. }\end{array}$ & & & \\
\hline $\begin{array}{l}\text { Air temperature and } \\
\text { flow control }\end{array}$ & $\begin{array}{l}\text { At least six steerable supply vents } \\
\text { with } \pm 5^{\circ} \mathrm{F} \text { variation from habitat } \\
\text { ambient temperature and 3-setting } \\
\text { boost fan }\end{array}$ & & & \\
\hline
\end{tabular}

22

American Institute of Aeronautics and Astronautics 


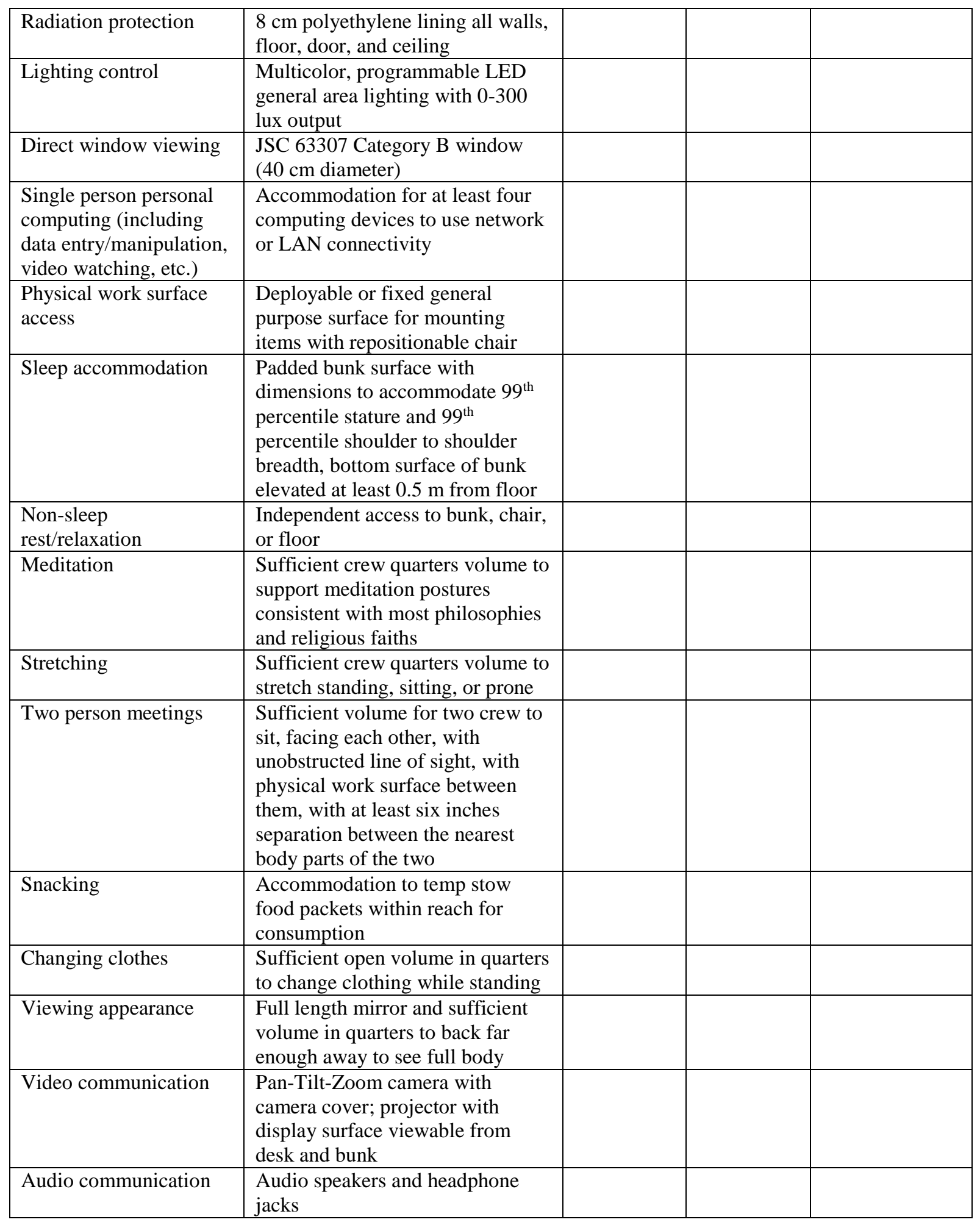

For any spacecraft development, the Capability and Capability Description columns must be completed for each matrix, with a separate Function Capability Matrix needed for each of the previously mentioned living and working functions. The capability descriptions must be tailored for the specific type of habitat in development. The capability descriptions shown in the Table 1 example above would of course be different for a 30-day Lunar Outpost. It is then 
necessary to obtain pros, cons, comments, and unknowns from SMEs of each of the appropriate categories for each function. It is likely there will be conflicting opinions. Follow-on discussions may be necessary to clarify information, but no effort should be made to convince conflicting SMEs to agree with one another.

It must be noted that the Function Capability Matrix does not indicate how many crew should perform any given capability at a time, or which capabilities should be able to be performed in parallel with each other. With inputs to the Function Capability Matrices from the appropriate SMEs the process can begin to make an informed decision with respect to the inclusion or exclusion of specific capabilities for each crew function. One or more vehicle layout concepts can then be completed by the designer as part of this process.

\section{Recommended Capability Verification}

It will often be necessary to verify pros and cons or resolve unknowns and differences of opinion among SMEs with testing. Divergent SME opinions can help guide the development of competing vehicle architectures. These architectures can be compared with human-in-the-loop testing by means of table-top reviews, relatively short duration virtual reality (VR) or part task mockup testing, multi-day mission operations simulations in medium to high fidelity spacecraft mockups. Generally these comparisons are applied progressively, with higher fidelity testing occurring after initial down selections and cycles of design refinement. Reports from each of these tests can provide the objective data to guide down selections of concepts and provide quantifiable justification for the ultimately selected function capabilities.

\section{Conclusion}

The Function Capability Matrix is a tool that is hoped to aid in the development of vehicles for human spaceflight. It is recommended that the matrix be utilized in NASA, commercial, and other spacecraft development efforts to further refine the tool and increase its effectiveness.

The first step for spacecraft design teams to begin to use this tool is to perform a functional analysis to determine the recommended living and working functions to include in the spacecraft. Next, develop a Function Capability Matrix for each function, completing the capability and capability description columns. Provide the matrices to appropriate SMEs for completion of the pros, cons, and comments/unknowns columns. Conduct follow-on communication with SMEs to clarify SME inputs as needed; do not attempt to resolve conflicts. SMEs will naturally be expected to have divergent opinions for each proposed capability description - some will support it as proposed, others will disagree, some may propose or suggest alternative descriptions.

Use conflicting SME inputs as a means to develop a manageable number of sets (perhaps no more than a dozen) of proposed functional capabilities. For instance, one set of SME recommendations may propose very limited capabilities while another set may propose very extensive capabilities. Develop a high level spacecraft concept for each set of proposed functional capabilities. Effectively this becomes a trade space of spacecraft concepts that reflect the divergence of opinion in the SME data.

Conduct a table-top review of these spacecraft concepts to narrow these initial concepts down to a set of perhaps no more than four. Document the SME-identified pros and cons that differentiate them from each other and identify any capabilities (and resulting pros and cons) that were eliminated during the down select and are not present in any of the remaining concepts.

Develop low fidelity part task mockups and low to medium fidelity virtual environments for these concepts and conduct VR and mockup assessments. Based on evaluation data, down select to a single concept. Identify capabilities (and resulting pros and cons) that were eliminated during the down select and are not present in the remaining concept. Discuss these capabilities and any supporting evaluation or SME data with appropriate SMEs to verify the validity of eliminating these capabilities.

Design and construct a medium to high fidelity spacecraft mockup for this final concept. Conduct a series of increasing duration mission operations simulations with this mockup and refine the spacecraft design between simulations, based on evaluation data.

This process can be applied wholly or in part, based on program funding available. For flight programs the entire process can be completed, while for limited concept studies there may be no progression beyond tabletop reviews or perhaps VR testing. While the motivation for this effort is to advance capability for missions beyond LEO, it is applicable to any long duration spacecraft, whether a microgravity transit vehicle, a planetary surface outpost, or an orbital space station. 


\section{Appendix}

Tables 2-15 provide template Function Capability Matrices for each of the living and working functions described in this paper.

Table 2 Private Habitation Function Capability Matrix

\begin{tabular}{|l|l|l|l|l|}
\hline Capability & $\begin{array}{l}\text { Capability } \\
\text { Description }\end{array}$ & Pros & Cons & Unknowns \\
\hline Visual separation & & & & \\
\hline Auditory separation & & & & \\
\hline Olfactory separation & & & & \\
\hline Tactile separation & & & & \\
\hline $\begin{array}{l}\text { Air temperature and } \\
\text { flow control }\end{array}$ & & & & \\
\hline Radiation protection & & & & \\
\hline Lighting control & & & & \\
\hline Direct window viewing & & & & \\
\hline $\begin{array}{l}\text { Single person personal } \\
\text { computing (including } \\
\text { data entry/manipulation, } \\
\text { video watching, etc.) }\end{array}$ & & & & \\
\hline $\begin{array}{l}\text { Physical work surface } \\
\text { access }\end{array}$ & & & & \\
\hline Sleep accommodation & & & & \\
\hline $\begin{array}{l}\text { Non-sleep } \\
\text { rest/relaxation }\end{array}$ & & & & \\
\hline Meditation & & & & \\
\hline Stretching & & & & \\
\hline Two person meetings & & & & \\
\hline Snacking & & & & \\
\hline Changing clothes & & & & \\
\hline Viewing appearance & & & & \\
\hline Video communication & & & & \\
\hline Audio communication & & & & \\
\hline
\end{tabular}

Table 3 Hygiene Function Capability Matrix

\begin{tabular}{|l|l|l|l|l|}
\hline Capability & $\begin{array}{l}\text { Capability } \\
\text { Description }\end{array}$ & Pros & Cons & Unknowns \\
\hline Visual separation & & & & \\
\hline Auditory separation & & & & \\
\hline Olfactory separation & & & & \\
\hline Tactile separation & & & & \\
\hline $\begin{array}{l}\text { Air temperature and } \\
\text { flow control }\end{array}$ & & & & \\
\hline Lighting control & & & & \\
\hline Full body cleaning & & & & \\
\hline Facial cleaning & & & & \\
\hline Hand cleaning & & & & \\
\hline $\begin{array}{l}\text { Physical work surface } \\
\text { access }\end{array}$ & & & & \\
\hline Viewing appearance & & & & \\
\hline
\end{tabular}

25

American Institute of Aeronautics and Astronautics 


\begin{tabular}{|l|l|l|l|l|}
\hline Oral hygiene & & & & \\
\hline Shaving & & & & \\
\hline Hair styling/grooming & & & & \\
\hline Finger/toe nail clipping & & & & \\
\hline Skin care & & & \\
\hline
\end{tabular}

Table 4 Human Waste Collection Function Capability Matrix

\begin{tabular}{|l|l|l|l|l|}
\hline Capability & $\begin{array}{l}\text { Capability } \\
\text { Description }\end{array}$ & Pros & Cons & Unknowns \\
\hline Visual separation & & & & \\
\hline Auditory separation & & & & \\
\hline Olfactory separation & & & & \\
\hline Tactile separation & & & & \\
\hline $\begin{array}{l}\text { Air temperature and } \\
\text { flow control }\end{array}$ & & & & \\
\hline Lighting control & & & & \\
\hline Liquid waste collection & & & & \\
\hline Solid waste collection & & & & \\
\hline $\begin{array}{l}\text { Private bodily self- } \\
\text { inspection and cleaning }\end{array}$ & & & & \\
\hline Hand cleaning & & & & \\
\hline $\begin{array}{l}\text { Facility/equipment } \\
\text { cleaning/sanitation and } \\
\text { maintenance }\end{array}$ & & & & \\
\hline
\end{tabular}

Table 5 Meal Preparation Function Capability Matrix

\begin{tabular}{|l|l|l|l|l|}
\hline Capability & $\begin{array}{l}\text { Capability } \\
\text { Description }\end{array}$ & Pros & Cons & Unknowns \\
\hline $\begin{array}{l}\text { Air temperature and } \\
\text { flow control }\end{array}$ & & & & \\
\hline Lighting control & & & & \\
\hline Rehydration & & & & \\
\hline Food warming & & & & \\
\hline Food item sorting & & & & \\
\hline $\begin{array}{l}\text { Utensil and food } \\
\text { equipment hygiene }\end{array}$ & & & & \\
\hline $\begin{array}{l}\text { Facility/equipment } \\
\text { cleaning/sanitation and } \\
\text { maintenance }\end{array}$ & & & & \\
\hline Plant growth & & & & \\
\hline Plant harvesting & & & & \\
\hline Plant processing & & & & \\
\hline Aquatic animal growth & & & & \\
\hline Small animal growth & & & & \\
\hline Meat processing & & & & \\
\hline Food packaging & & & & \\
\hline Food chilling & & & & \\
\hline Food cooking & & & & \\
\hline
\end{tabular}

Table 6 Meal Consumption Function Capability Matrix

American Institute of Aeronautics and Astronautics 


\begin{tabular}{|l|l|l|l|l|}
\hline Capability & $\begin{array}{l}\text { Capability } \\
\text { Description }\end{array}$ & Pros & Cons & Unknowns \\
\hline $\begin{array}{l}\text { Air temperature and flow } \\
\text { control }\end{array}$ & & & & \\
\hline Lighting control & & & & \\
\hline $\begin{array}{l}\text { Full crew } \\
\text { accommodation/restraint }\end{array}$ & & & & \\
\hline Dining surface & & & & \\
\hline $\begin{array}{l}\text { Accessible mounting of } \\
\text { condiments }\end{array}$ & & & & \\
\hline Direct window viewing & & & & \\
\hline Audio display & & & & \\
\hline Video display & & & & \\
\hline
\end{tabular}

Table 7 Group Socialization and Recreation Function Capability Matrix

\begin{tabular}{|l|l|l|l|l|}
\hline Capability & $\begin{array}{l}\text { Capability } \\
\text { Description }\end{array}$ & Pros & Cons & Unknowns \\
\hline $\begin{array}{l}\text { Air temperature and } \\
\text { flow control }\end{array}$ & & & & \\
\hline Lighting control & & & & \\
\hline Direct window viewing & & & & \\
\hline Video/movie viewing & & & & \\
\hline Computer based games & & & & \\
\hline Tabletop games & & & & \\
\hline Athletic games & & & & \\
\hline $\begin{array}{l}\text { Artistic/creative } \\
\text { recreation }\end{array}$ & & & & \\
\hline
\end{tabular}

Table 8 Exercise Function Capability Matrix

\begin{tabular}{|l|l|l|l|l|}
\hline Capability & $\begin{array}{l}\text { Capability } \\
\text { Description }\end{array}$ & Pros & Cons & Unknowns \\
\hline Visual separation & & & & \\
\hline Auditory separation & & & & \\
\hline Olfactory separation & & & & \\
\hline Tactile separation & & & & \\
\hline $\begin{array}{l}\text { Air temperature and } \\
\text { flow control }\end{array}$ & & & & \\
\hline Lighting control & & & & \\
\hline Aerobic exercise & & & & \\
\hline Resistive exercise & & & & \\
\hline Bone loading & & & & \\
\hline $\begin{array}{l}\text { Sensorimotor } \\
\text { conditioning }\end{array}$ & & & & \\
\hline Sweat barricade & & & & \\
\hline Audio display & & & & \\
\hline Video display & & & & \\
\hline Data entry & & & & \\
\hline
\end{tabular}

Table 9 Medical Operations Function Capability Matrix

\begin{tabular}{|l|l|l|l|l|}
\hline Capability & $\begin{array}{l}\text { Capability } \\
\text { Description }\end{array}$ & Pros & Cons & Unknowns \\
\hline
\end{tabular}

27

American Institute of Aeronautics and Astronautics 


\begin{tabular}{|l|l|l|l|l|}
\hline Visual separation & & & & \\
\hline Auditory separation & & & & \\
\hline Olfactory separation & & & & \\
\hline Tactile separation & & & & \\
\hline Data separation & & & & \\
\hline $\begin{array}{l}\text { Air temperature and } \\
\text { flow control }\end{array}$ & & & & \\
\hline Lighting control & & & & \\
\hline Audio communication & & & & \\
\hline Video communication & & & & \\
\hline Private telemedicine & & & & \\
\hline $\begin{array}{l}\text { Computer data entry / } \\
\text { manipulation }\end{array}$ & & & & \\
\hline Two person meetings & & & & \\
\hline Space motion sickness & & & & \\
\hline First aid & & & & \\
\hline Anaphylaxis response & & & & \\
\hline Clinical diagnostics & & & & \\
\hline Ambulatory care & & & & \\
\hline Trauma care & & & & \\
\hline Medical imaging & & & & \\
\hline Dental care & & & & \\
\hline $\begin{array}{l}\text { Autonomous advanced } \\
\text { life support }\end{array}$ & & & & \\
\hline Basic surgical care & & & & \\
\hline
\end{tabular}

Table 10 Scientific Research Function Capability Matrix

\begin{tabular}{|l|l|l|l|l|}
\hline Capability & $\begin{array}{l}\text { Capability } \\
\text { Description }\end{array}$ & Pros & Cons & Unknowns \\
\hline Visual separation & & & & \\
\hline Auditory separation & & & & \\
\hline $\begin{array}{l}\text { Air temperature and flow } \\
\text { control }\end{array}$ & & & & \\
\hline Lighting control & & & & \\
\hline $\begin{array}{l}\text { Computer display and } \\
\text { control interface }\end{array}$ & & & & \\
\hline $\begin{array}{l}\text { Physical work surface } \\
\text { access }\end{array}$ & & & & \\
\hline Telescience & & & & \\
\hline Direct window viewing & & & & \\
\hline Video communication & & & & \\
\hline Audio communication & & & & \\
\hline $\begin{array}{l}\text { Human factors and } \\
\text { habitability }\end{array}$ & & & & \\
\hline Food \& nutrition & & & & \\
\hline $\begin{array}{l}\text { Human health } \\
\text { countermeasures }\end{array}$ & & & & \\
\hline Space radiation & & & & \\
\hline Environmental health & & & & \\
\hline $\begin{array}{l}\text { Cellular and molecular } \\
\text { biology }\end{array}$ & & & & \\
\hline Botany & & & & \\
\hline
\end{tabular}

American Institute of Aeronautics and Astronautics 


\begin{tabular}{|l|l|l|l|l|}
\hline Animal science & & & & \\
\hline Entomology & & & & \\
\hline Mammalogy & & & & \\
\hline Herpetology & & & & \\
\hline Ornithology & & & & \\
\hline Ethology & & & & \\
\hline Zoography & & & & \\
\hline Biotechnology & & & & \\
\hline Genetics & & & & \\
\hline Mycology & & & & \\
\hline Chemistry & & & & \\
\hline Acoustics & & & & \\
\hline Cryogenics & & & & \\
\hline Combustion & & & & \\
\hline Fluid science & & & & \\
\hline Materials science & & & & \\
\hline Physics & & & & \\
\hline Optics & & & & \\
\hline Astronomy/astrophysics & & & & \\
\hline Heliophysics & & & \\
\hline Meteorology & & & & \\
\hline Planetary science & & & & \\
\hline In-situ resource utilization & & & & \\
\hline Robotics / teleoperation & & & & \\
\hline $\begin{array}{l}\text { Engineering/technology } \\
\text { prototyping and testing }\end{array}$ & & & & \\
\hline
\end{tabular}

Table 11 EVA Operations Function Capability Matrix

\begin{tabular}{|l|l|l|l|l|}
\hline Capability & $\begin{array}{l}\text { Capability } \\
\text { Description }\end{array}$ & Pros & Cons & Unknowns \\
\hline Depressurization & & & & \\
\hline Repressurization & & & & \\
\hline Hyperbaric isolation & & & & \\
\hline Hypobaric isolation & & & & \\
\hline $\begin{array}{l}\text { Air temperature and } \\
\text { flow control }\end{array}$ & & & & \\
\hline Lighting control & & & & \\
\hline $\begin{array}{l}\text { EVA suit donning and } \\
\text { doffing }\end{array}$ & & & & \\
\hline Crew ingress/egress & & & & \\
\hline Robot ingress/egress & & & & \\
\hline $\begin{array}{l}\text { Subsystem or payload } \\
\text { ingress/egress }\end{array}$ & & & & \\
\hline Suit servicing & & & & \\
\hline Suit repair & & & & \\
\hline Suit component testing & & & & \\
\hline IVA support of EVA & & & & \\
\hline $\begin{array}{l}\text { Computer display and } \\
\text { control interface }\end{array}$ & & & & \\
\hline Video communication & & & & \\
\hline Audio communication & & & & \\
\hline
\end{tabular}

American Institute of Aeronautics and Astronautics 
Table 12 Spacecraft Monitoring and Commanding Function Capability Matrix

\begin{tabular}{|l|l|l|l|l|}
\hline Capability & $\begin{array}{l}\text { Capability } \\
\text { Description }\end{array}$ & Pros & Cons & Unknowns \\
\hline Visual separation & & & & \\
\hline Auditory separation & & & & \\
\hline Data separation & & & & \\
\hline $\begin{array}{l}\text { Air temperature and } \\
\text { flow control }\end{array}$ & & & & \\
\hline Lighting control & & & & \\
\hline Piloting & & & & \\
\hline Teleoperation & & & & \\
\hline $\begin{array}{l}\text { Computer display and } \\
\text { control interface }\end{array}$ & & & & \\
\hline $\begin{array}{l}\text { Subsystem manual } \\
\text { display and control } \\
\text { interface }\end{array}$ & & & & \\
\hline Direct window viewing & & & & \\
\hline Video communication & & & & \\
\hline Audio communication & & & & \\
\hline
\end{tabular}

Table 13 Mission Planning Function Capability Matrix

\begin{tabular}{|l|l|l|l|l|}
\hline Capability & $\begin{array}{l}\text { Capability } \\
\text { Description }\end{array}$ & Pros & Cons & Unknowns \\
\hline Visual separation & & & & \\
\hline Auditory separation & & & & \\
\hline Data separation & & & & \\
\hline $\begin{array}{l}\text { Air temperature and } \\
\text { flow control }\end{array}$ & & & & \\
\hline Lighting control & & & & \\
\hline $\begin{array}{l}\text { Physical work surface } \\
\text { access }\end{array}$ & & & & \\
\hline $\begin{array}{l}\text { Computer display and } \\
\text { control interface }\end{array}$ & & & & \\
\hline Video communication & & & & \\
\hline Audio communication & & & \\
\hline
\end{tabular}

Table 14 Maintenance and Fabrication

\begin{tabular}{|l|l|l|l|l|}
\hline Capability & $\begin{array}{l}\text { Capability } \\
\text { Description }\end{array}$ & Pros & Cons & Unknowns \\
\hline Visual separation & & & & \\
\hline Auditory separation & & & & \\
\hline $\begin{array}{l}\text { Air temperature and } \\
\text { flow control }\end{array}$ & & & & \\
\hline Lighting control & & & & \\
\hline $\begin{array}{l}\text { Dust/particle/fume } \\
\text { mitigation }\end{array}$ & & & & \\
\hline Debris capture & & & & \\
\hline Air filtration & & & & \\
\hline $\begin{array}{l}\text { Computer display and } \\
\text { control interface }\end{array}$ & & & & \\
\hline
\end{tabular}

30

American Institute of Aeronautics and Astronautics 


\begin{tabular}{|l|l|l|l|l|}
\hline $\begin{array}{l}\text { Physical work surface } \\
\text { access }\end{array}$ & & & & \\
\hline Telemaintenance & & & & \\
\hline Video communication & & & & \\
\hline Audio communication & & & & \\
\hline Material handling & & & & \\
\hline Component sterilization & & & & \\
\hline Component isolation & & & & \\
\hline Housekeeping & & & & \\
\hline Soldering & & & & \\
\hline Brazing & & & & \\
\hline Welding & & & & \\
\hline 3D printing & & & & \\
\hline CNC fabrication & & & & \\
\hline Material drilling & & & & \\
\hline Material cutting & & & & \\
\hline $\begin{array}{l}\text { Material rolling and } \\
\text { bending }\end{array}$ & & & & \\
\hline Material fastening & & & & \\
\hline Thermoplastic forming & & & & \\
\hline $\begin{array}{l}\text { Soft goods sewing, } \\
\text { cutting, and patching }\end{array}$ & & & & \\
\hline Surface bonding & & & & \\
\hline Materials analysis & & & & \\
\hline Electronics analysis & & & & \\
\hline Component testing & & & & \\
\hline CAD modeling & & & & \\
\hline Software coding & & & & \\
\hline
\end{tabular}

Table 15 Logistics Function Capability Matrix

\begin{tabular}{|l|l|l|l|l|}
\hline Capability & $\begin{array}{l}\text { Capability } \\
\text { Description }\end{array}$ & Pros & Cons & Unknowns \\
\hline $\begin{array}{l}\text { Air temperature and } \\
\text { flow control }\end{array}$ & & & & \\
\hline Lighting control & & & & \\
\hline $\begin{array}{l}\text { Stowage temperature } \\
\text { control }\end{array}$ & & & & \\
\hline $\begin{array}{l}\text { Computer display and } \\
\text { control interface }\end{array}$ & & & & \\
\hline $\begin{array}{l}\text { Physical work surface } \\
\text { access }\end{array}$ & & & & \\
\hline Bulk stowage & & & & \\
\hline Temporary stowage & & & & \\
\hline $\begin{array}{l}\text { Workstation } \\
\text { integrated stowage }\end{array}$ & & & & \\
\hline $\begin{array}{l}\text { Small item } \\
\text { containment }\end{array}$ & & & & \\
\hline Dry trash stowage & & & & \\
\hline Wet trash stowage & & & & \\
\hline $\begin{array}{l}\text { Biologically active } \\
\text { trash stowage }\end{array}$ & & & & \\
\hline Human waste stowage & & & & \\
\hline
\end{tabular}

31

American Institute of Aeronautics and Astronautics 


\begin{tabular}{|l|l|l|l|l|}
\hline Toxic trash stowage & & & \\
\hline $\begin{array}{l}\text { Robotic logistics } \\
\text { transfer }\end{array}$ & & & & \\
\hline Bulk logistics transfer & & & & \\
\hline Position tracking & & & & \\
\hline $\begin{array}{l}\text { Inventory } \\
\text { management }\end{array}$ & & & \\
\hline
\end{tabular}

\section{References}

[1] Mckern, R. A., Brown, D. G., Dove, D. W., Gilmore, J. P., Landey, M. E., Musoff, H., Amand, J. S., Vincent, K. T., Jr., "Space Shuttle Avionics: a Redundant IMU On-Board Checkout and Redundancy Management System," Charles Stark Draper Laboratory, Massachusetts Institute of Technology, Cambridge, MA, 1972.

[2] Office of the Assistant Secretary of Defense for Logistics \& Materiel Readiness, "Maintenance Overview", DASD Maintenance Policy \& Programs, Washington, https://www.acq.osd.mil//og/mpp/maintenance_overview.html [Retrieved 15 May 2018].

[3] Levi, R., "The Awful and Wonderful History of the Mir Space Station," Curious Minds science, technology \& history, URL: https://www.cmpod.net/the-awful-and-wonderful-history-of-the-mir-space-station-curious-mindspodcast/ [retrieved 27 July 2018].

[4] Holliman, J., Aaron, B., and Doughtery, J., "Mir at half power after collision," CNN, URL: http://www.cnn.com/TECH/9706/25/mir.collision.4p/index.html, [retrieved 27 July 2018].

[5] National Aeronautics and Space Administration, "NASA Space Flight Human-System Standard Volume 2: Human Factors, Habitability, and Environmental Health,” NASA Technical Standard NASA-STD-3001, Volume 2, 2011.

[6] National Aeronautics and Space Administration, "EVA Office Extracurricular Activity (EVA) Airlocks and Alternate Ingress/Egress Methods Document," EVA-EXP-0031, 2018.

[7] National Aeronautics and Space Administration, "EVA Office Exploration EVA System Compatibility," EVA-EXP-0035, 2018. 